\title{
Is a Poor Quality Nutrition Environment a Contributor to Obesity Prevalence in School-Age-Children in West Virginia?
}

Anna M. Chetrick

West Virginia University

Follow this and additional works at: https://researchrepository.wvu.edu/etd

\section{Recommended Citation}

Chetrick, Anna M., "Is a Poor Quality Nutrition Environment a Contributor to Obesity Prevalence in SchoolAge-Children in West Virginia?" (2011). Graduate Theses, Dissertations, and Problem Reports. 3273. https://researchrepository.wvu.edu/etd/3273

This Thesis is protected by copyright and/or related rights. It has been brought to you by the The Research Repository @ WVU with permission from the rights-holder(s). You are free to use this Thesis in any way that is permitted by the copyright and related rights legislation that applies to your use. For other uses you must obtain permission from the rights-holder(s) directly, unless additional rights are indicated by a Creative Commons license in the record and/ or on the work itself. This Thesis has been accepted for inclusion in WVU Graduate Theses, Dissertations, and Problem Reports collection by an authorized administrator of The Research Repository @ WVU. For more information, please contact researchrepository@mail.wvu.edu. 


\title{
Is a Poor Quality Nutrition Environment a Contributor to Obesity Prevalence in School-Age-Children in West Virginia?
}

\author{
Anna M. Chetrick
}

A thesis submitted to Davis College of Agriculture, Natural Resources and Design at West Virginia University in partial fulfillment of the requirements for the degree of

Master of Science

in

Animal \& Nutritional Sciences

Committee Members

Susan Partington, $\mathrm{PhD}, \mathrm{RD}$, Chair

Janet Tou, $\mathrm{PhD}$

Melissa Olfert, DrPH, MS, RD

Division of Animal and Nutritional Sciences

Morgantown, West Virginia

2011

Keywords: nutrition environment, obesity, children, body mass index, poverty, retail food

(C) 2011 Anna M. Chetrick 


\begin{abstract}
Is a Poor Quality Nutrition Environment a Contributor to Obesity Prevalence in SchoolAge-Children in West Virginia?
\end{abstract}

\author{
Anna M. Chetrick
}

In recent years there has been considerable interest in describing and explaining increases in the prevalence of overweight and obesity. The quality of the nutrition environment, including the availability and price of healthy foods options, has been suggested as a likely contributor. This project was developed to investigate the relationship between weight status and the nutrition environment in school children in two West Virginia counties. The Nutrition Environment Measures Survey (NEMS) was conducted in Monongalia and Marshall Counties, WV. From NEMS survey data nutrition environment quality scores were calculated for 79 retail food outlets, including grocery, convenience, general, and department stores. Availability, cost, and quality were compared among store type and area-level (Census tract) poverty. Child and parent $\mathrm{BMI}$, eating and physical activity habits, and child, parent and family socio-demographic characteristics were obtained from the 2009-2010 Coronary Artery Detection in Rural Appalachian Communities (CARDIAC) study screening and Parent Survey. There were no differences in availability of healthy food options or overall nutrition environment scores by area-level poverty, but there were significant differences by store type. Logistic regression was used to examine relationships between child BMI and the nutrition environment controlling for known covariates. Children with an overweight or obese parent (OR 3.8, $p<0.01)$ and in families with annual incomes less than $\$ 50,000$ (OR 2.6, $p<0.05$ ) were more likely to be obese and those with moderate physical activity on a regular basis (OR $0.09, p<0.05)$ less likely. The results indicate the strength of familial genetic and environmental factors as contributors to child weight status as well as the importance of regular physical activity. The nutrition environment, when defined as the quality of retail food outlets within the Census tract of residence, appears to have little impact on weight status in children. 


\section{ACKNOWLEDGMENTS}

I would first like to thank my advisor, Dr. Susan Partington for giving me this opportunity and providing me with the tools necessary to complete this task. I would also like to thank my committee members, Dr. Janet Tou and Dr. Melissa Olfert for their useful feedback and continued encouragement. I express great appreciation to Dr. Gianfranco Piras, Dr. Donald Lacombe, and Mark Middleton for their time and efforts in the geocoding process and analysis. I would like to extend a special thank you to Janie Leary and Dr. Lesley Cottrell from CARDIAC for sharing their office space and allowing me to use their equipment. I would like to thank all of the raters, Michelle McGinley, Karina Walker, and Trevor Standiford for their work on the surveys. I truly appreciate all their help. I want to thank all of the interns for their constant support, encouragement, and friendship. I also want to thank Adam Lensmire for always pushing me and motivating me to never give up. And finally, I thank my family for their financial and emotional support during the past two years. 


\section{TABLE OF CONTENTS}

\section{Page}

ABSTRACT

ii

ACKNOWLEDGEMENTS

iii

TABLE OF CONTENTS

iv

LIST OF TABLES

vii

LIST OF ABBREVIATIONS

viii

1.0 INTRODUCTION 1

2.0 STUDY HYPOTHESIS AND OBJECTIVES 2

3.0 LITERATURE REVIEW 3

3.1. Prevalence of overweight among children and adolescents in the United

States

3

3.2. Risk factors associated with overweight and obesity

3.3. Socioeconomic status and obesity prevalence

7

3.4. Retail food accessibility, availability, and cost

9

3.5. Proximity to supermarket and fruit and vegetable intake

10

3.6. Summary

11 
4.0. MATERIALS AND METHODS 12

4.1. Enumeration of stores $\quad 12$

4.2. Assessment of food availability, price, and quality 13

4.3. Reliability testing $\quad 14$

4.4. Comparison items 14

4.5. Nutrition environment quality scores $\quad 15$

4.6. BMI percentiles and measurement scores $\quad 15$

4.7. Statistical analysis 16

$\begin{array}{ll}\text { 5.0. RESULTS } & 18\end{array}$

$\begin{array}{ll}\text { 5.1. Population characteristics } & 18\end{array}$

$\begin{array}{ll}\text { 5.2. Sample characteristics } & 18\end{array}$

5.3. Availability of healthier options 19

5.4. Cost comparison of healthier vs. regular options 19

$\begin{array}{ll}\text { 5.5. NEMS-S scores } & 20\end{array}$

5.6. Association of nutrition environment with obesity prevalence 20

6.0. DISCUSSION 22 
7.0. LIMITATIONS

8.0. SUMMARY AND CONCLUSION

9.0. REFERENCES 


\section{LIST OF TABLES}

Table 1: Stores Removed from Analysis

Table 2: Number and Type of Stores Surveyed by County

Table 3: Comparison Items

Table 4: Price Measurements

Table 5: Number of Stores by Poverty Quartile

Table 6: Availability of Healthier Options by Store Type

Table 7: Availability of Healthier Options by Percent Poverty Threshold

Table 8: Cost Comparison of Healthier vs. Regular Options by Store Type

Table 9: Cost Comparison of Healthier vs. Regular Options by Percent Poverty Threshold

Table 10: NEMS Composite Mean Scores for Healthy Nutrition Environments in Stores

Table 11: NEMS Composite Mean Scores for Stores by Census Tract Poverty Level

Table 12: Demographic Characteristics and Weight Status CARDIAC Participants 2009-2010

Table 13: Parent Survey Response CARDIAC Questionnaire

Table 14: Demographic Characteristics Questionnaire Respondents and Counties

Table 15: Odds Ratios for Risk of Obesity from Logistic Regression Analysis 


\section{LIST OF ABBREVIATIONS}

BMI

SES

PA

NHANES

USDA

OR

NEMS

NEMS-S

NEMS-R

CARDIAC

Kcals
Body Mass Index

Socioeconomic Status

Physical Activity

National Health and Nutrition Examination Surveys

United States Department of Agriculture

Odds Ratio

Nutrition Environment Measures Surveys

Nutrition Environment Measures Surveys-Stores

Nutrition Environment Measures Surveys-Restaurants

Coronary Artery Risk Detection in Appalachian Communities

Kilocalories 


\subsection{Introduction}

There are numerous factors that may contribute to obesity. Individual-level dietary patterns, physical activity, sedentary behavior, genetics, socio-economic status, cultural heritage, and the nutrition and physical activity environments are among the characteristics that have been examined as causal factors. During recent decades, the prevalence of pediatric overweight and obesity in the United States has increased significantly. ${ }^{1}$ Change in the food or nutrition environment has been identified as a likely contributor to this trend. The community nutrition environment is generally defined as the availability and cost of food in one's area of residence or neighborhood. Numerous studies have suggested that community-level availability, affordability, and quality of food may be related to weight status by influencing food choice and consequently food intake. ${ }^{2-5}$ High energy density foods (fats and refined carbohydrates) are less costly than those low in energy density (low-fat meat, dairy, fruits and vegetables). ${ }^{6}$ It is important to determine if the nutrition environment is a substantial contributor to weight status so that appropriate programs and policies may be developed and implemented for the prevention and management of obesity in children and adolescents in the United States (US). 


\subsection{Study Hypothesis and Objectives}

Areas of high poverty in Marshall and Monongalia Counties of West Virginia have a lower quality nutrition environment, specifically; lower availability to and higher cost of healthy food options compared to areas of low poverty in these counties. These environmental factors may contribute to a higher prevalence of overweight and obesity in children in areas of high poverty.

In order to test the hypothesis the study objectives were:

1. To determine if healthy food options are more available and less costly in areas of low poverty compared to areas of high poverty.

2. To determine if the quality of the local nutrition environment is significantly associated with the prevalence of overweight and obesity in children controlling for individual- and area-level household income. 


\subsection{Literature Review}

\subsection{Prevalence of Overweight among Children and Adolescents in the}

\section{United States}

Obesity continues to be a leading public health concern as prevalence continues to increase in the United States. ${ }^{7}$ Children with a body mass index (BMI) between the $85^{\text {th }}$ and $95^{\text {th }}$ percentiles are considered overweight. Children are obese if their BMI is $\geq 95^{\text {th }}$ percentile. ${ }^{8}$ Children and adolescents who are overweight are more likely to become obese adults and to develop type 2 diabetes, cardiovascular disease, hypertension, hyperlipidemia, asthma, and sleep apnea. ${ }^{9}$

Between 1980 and 2002, overweight prevalence tripled in children and adolescents aged 6 to 19 years in the US. ${ }^{7}$ Data from the National Health and Nutrition Examination Surveys (NHANES) indicated that $17.1 \%$ of children and adolescents aged 2 to 19 years were obese (BMI $\geq 95^{\text {th }}$ percentile for age) in 2003-2004. ${ }^{7}$ Tests of trend using logistic regression adjusted for age and race/ethnicity showed a significant increase in prevalence of overweight in children and adolescents aged 2 to 19 over years 1999-2000, 2001-2002, and 2003-2004 ( $p=0.0396$ for males and $p=0.0463$ for females). ${ }^{7}$

Flegal et al. ${ }^{10}$ used dual-energy X-ray absorptiometry in 8,821 children and adolescents aged 8-19 years to measure body fat percentage. They found that most children with high BMIfor-age ( $\geq 95^{\text {th }}$ percentile) had high adiposity, and few children with normal BMI-for-age $\left(<85^{\text {th }}\right.$ percentile) had high adiposity. The prevalence of high adiposity in intermediate BMI categories varied from $45 \%$ to $15 \%$ depending on the cutoff. The prevalence of a high BMI was significantly higher in non-Hispanic black girls than in non-Hispanic white girls, but the prevalence of high adiposity was not significantly different between the groups. ${ }^{10}$ 
Singh et al. ${ }^{11}$ found $16.4 \%$ of US children to be obese and $31.6 \%$ overweight in 2007. The prevalence of obesity varied substantially across the 50 states, with Mississippi having the highest prevalence $(21.9 \%)$ and Oregon the lowest prevalence $(9.6 \%)$. Overweight prevalence among children and adolescents aged 10 to 17 years in West Virginia was $35.5 \%$ in 2007 and obesity prevalence was $18.9 \%$. Between 2003 and 2007, obesity prevalence increased by $10 \%$ for all US children, 18\% for female children and 6\% for males. West Virginia children had more than twice the adjusted odds of being obese than children in Oregon. Individual, household, and neighborhood social and built environmental characteristics accounted for $45 \%$ and $42 \%$ of the state variance in childhood obesity and overweight, respectively. ${ }^{11}$

\subsection{Risk Factors Associated with Overweight and Obesity}

\section{$\underline{\text { Dietary Patterns }}$}

Numerous studies have documented increasingly poor dietary behaviors among adolescents, including an excess intake of fat, sugar, snacks, soda, and fast food ${ }^{12}$ and a low intake of fruit and vegetables. ${ }^{13,14}$ Other dietary patterns contributing to overweight among children are increased intakes of sugar-sweetened beverages ${ }^{15,16}$ and larger portion sizes. ${ }^{17}$ Mean calorie and fat intake have increased consistently over time among both children/adolescents and adults in the United States. ${ }^{18,19}$ Unhealthy food consumption patterns put youths at higher risk for overweight. $^{20,21}$

Using the USDA's 1994-96 Continuing Survey of Food Intakes by Individuals (CSFII) food consumption data and BMI data from the 1998 CSFII, Lin and Morrison ${ }^{22}$ found that overweight children and obese adults of both genders consumed significantly less fruit than their healthy-weight counterparts. In addition, at-risk-of-overweight girls also consumed less fruit 
than healthy-weight girls. ${ }^{22}$ It appears that fruit consumption is linked with lower body mass index.

\section{$\underline{\text { Sedentary Behavior }}$}

Sedentary behavior has been reported to promote and escalate overweight in children due to the effects on energy expenditure and energy intake. ${ }^{23}$ Sedentary behavior, often measured as screen time, may displace time children spend in physical activities, contribute to increased energy consumption through excessive snacking and eating meals in front of the television, and lower children's metabolic rate. ${ }^{24,25}$

Singh et al. ${ }^{11}$ found that children who watched television more than two hours per day had $48 \%$ higher odds of obesity and $56 \%$ higher odds of overweight than those who watched television less than one hour per day. Children who used a computer for more than two hours per day for purposes other than school work had $28 \%$ higher odds of obesity and $25 \%$ higher odds of overweight than those who used a computer for purposes other than school work less than one hour per day. Children who did not engage in any vigorous physical activity had at least $32 \%$ higher odds of obesity or overweight than those who exercised five or more days per week. $^{11}$

\section{$\underline{\text { Parental Weight }}$}

Obesogenic families, defined in terms of parents' activity and dietary patterns, can be used predict children's risk of obesity. ${ }^{26}$ Davison and Birch ${ }^{26}$ assessed a total of 197 girls and their parents when girls were 5 years old; 192 families were reassessed when girls were 7 years old. Measures of parents' physical activity and dietary intake were obtained and entered into a cluster analysis to assess whether distinct family clusters could be identified. Girls' skinfold thickness and BMI were also assessed and were used to examine the predictive validity of the 
clusters. Obesogenic and non-obesogenic family clusters were identified. Mothers and fathers in the obesogenic cluster reported high levels of dietary intake and low levels of physical activity, while mothers and fathers in the non-obesogenic cluster reported low levels of dietary intake and high levels of activity. Girls from families in the obesogenic cluster had significantly higher BMI and skinfold thickness values at age 7 and showed significantly greater increases in BMI and skinfold thickness from ages 5 to 7 years of age than girls from non-obesogenic families. ${ }^{26}$

In a retrospective cohort study, Whitaker et al. ${ }^{27}$ concluded that parental obesity more than doubles the risk of adult obesity among both obese and non-obese children less than 10 years of age. The chance of obesity in adulthood ranged from 8 percent for 1- or 2-year-olds without obese parents to 79 percent for 10-to-14-year-olds with at least one obese parent. After adjustment for the child's obesity status, the odds ratios for obesity in adulthood associated with having one obese parent ranged from 2.2 (95 percent confidence interval, 1.1 to 4.3 ) at 15 to 17 years of age to $3.2(1.8$ to 5.7$)$ at 1 or 2 years of age. ${ }^{27}$

Genetics also play an important role in determining body weight. In a 1997 review of the existing literature, Maes and colleagues ${ }^{28}$ found that family studies of parents and offspring and siblings reported (BMI) correlations indicating heritabilities of 20 to 80 percent. ${ }^{28}$ Heritability of BMI can be considered the proportion of variance in BMI due to inherited genetic factors. This same review found that data from adoption studies comparing adoptees to their adoptive and biological parents indicated that genetic factors accounted for $20-60 \%$ of the variation in BMI, and twin studies reported genetic factors to explain 50 to $90 \%$ of the variance in BMI. In their own analysis of 14,763 twins and family members, $67 \%$ of the variance in BMI was attributed to genetics. In a study of identical twins reared apart, Stunkard et al. ${ }^{29}$ found environmental factors explained about $30 \%$ of the variation in BMI. ${ }^{29}$ 


\subsection{Socioeconomic Status and Obesity Prevalence}

Socio-economic status has been associated with increased obesity prevalence. Mutunga et al. ${ }^{25}$ used a cross-sectional survey of 2,016 adolescents aged 12 years and 15 years selected from 36 schools in Northern Ireland in a random, stratified sample. BMI was used to measure obesity. Dietary intake was assessed using diet history with an open-ended interview and a photographic atlas to determine portion sizes. SES was determined from self-reported occupational information of the mother. Habitual physical activity, screen time, and cardiorespiratory fitness were measured to determine if there was a direct relationship among any of these behavioral risk factors and overweight. There were significantly higher daily energy intakes in the lower SES group. ${ }^{25}$

Wang et al. ${ }^{30}$, in an analysis of NHANES data (1971 to 2002) found inconsistent associations among race/ethnicity, poverty and weight status in children and adolescents aged 218 years old. The poverty income ratio from census block group was used as a measure of SES. The poverty income ratio is the household income divided by the poverty threshold. The poverty threshold is updated yearly and published by the Census Bureau. Subjects were separated into two age groups according to the World Health Organization's recommendation: children (2-9 years old) and adolescents (10-18 years old). They found not all low SES groups were at increased risk of overweight. Considerable racial, gender, and age differences existed. In children age 2-9 years old, none of the associations were significant. In adolescents aged 10-18 years old, there was a statistically significant inverse association between poverty ratio and overweight in white boys in NHANES II (1976-1980) and in white girls in NHANES III (19881994) $p<0.05, p<0.01$ respectively, showing that low SES groups were more likely to be overweight. Among black girls in NHANES (1999-2002) those with a high SES were twice as 
likely to be overweight than their counterparts with a medium SES. No significant associations were found in other gender-ethnicity groups or other rounds of the survey. ${ }^{30}$

Vieweg et al. ${ }^{31}$ investigated the association between overweight and SES in 29,824 public school children from 2002 to 2004. BMI was computed for students in kindergarten, third, seventh, and tenth grades. The percentage of the student population eligible for the free and reduced National School Lunch Program was used as a proxy for SES in elementary and middle school students. This program provides free or low-cost lunches to students based on the student's family size and income. Children from families with incomes at or below $130 \%$ of the poverty level are eligible for free meals. Those with incomes between $130 \%$ and $185 \%$ of the poverty level are eligible for reduced-price meals. The percentage of public school students eligible for free or reduced price lunches in a particular school was strongly related to child poverty among students of that school. To assess SES of high school students, the percentage of the school-age population living in poverty based on the per capita income data from the 2000 Census was used. Gender, race, and SES were important factors considered in this study and thought to contribute to the overweight prevalence. Boys were more likely than girls to be overweight. Hispanics had the highest prevalence of overweight followed by blacks while students classified as white were least likely to be overweight. ${ }^{31}$

Using data from the 1996 Healthy Survey for England, Wardle et al. ${ }^{32}$ examined socioeconomic predictors of obesity in men and women to compare odds ratios for obesity by education, occupation, and two economic markers after control for age, marital status, and ethnicity. In a multivariate logistic regression analysis, the authors found that obesity risk was greater among men and women with fewer years of education $(\mathrm{OR}=1.77$ and 1.81 , respectively) and poorer economic circumstances $(\mathrm{OR}=1.37$ for both) and among women, but not men, of 
lower occupational status $(p<0.01)$. Higher educational attainment and higher SES were associated with a lower risk of obesity in both men and women, whereas higher occupational status was associated with a lower risk only for women. ${ }^{32}$ These findings indicate that SES is an important determinant of weight status in both children and adults.

\subsection{Retail Food Accessibility, Availability and Cost}

It has been suggested that the influence of the nutrition environment on food intake involves two pathways: access to and cost of foods for home preparation from supermarkets and grocery stores, and access to and cost of ready-made food for home and out-of-home consumption (e.g. takeaways, restaurants). Accessibility to supermarkets is poorer in lowincome neighborhoods, with fewer supermarkets and more small independent grocery stores available to local residents. ${ }^{2}$

\section{$\underline{\text { Rural vs. Urban Areas }}$}

Food deserts, areas with low access to healthy foods, have become a major topic of interest among public health advocates as well as a dynamic and fast-growing field of research. Controlling for population density, rural areas have fewer food retailers of any type compared to urban areas, and only 14 percent the number of chain supermarkets. ${ }^{33}$ A nationwide analysis found that there are 418 rural - fod desert" counties where all residents live 10 miles or more from the nearest supermarket or supercenter, 20 percent of all rural counties. ${ }^{34}$

\section{$\underline{\text { Socioeconomic Status }}$}

A key determinant of weight status may be food cost. Low-cost foods tend to be energy dense and nutrient poor. ${ }^{6}$ The low cost of energy-dense foods along with easy access to such foods may explain high obesity prevalence among low SES communities. ${ }^{35}$ Research has shown 
that low-income neighborhoods attract more fast-food outlets ${ }^{36}$ and convenience stores as opposed to full-service supermarkets and grocery stores. ${ }^{37,38}$ Spence et al. ${ }^{3}$ found that a lower ratio of fast-food restaurants and convenience stores to grocery stores and produce vendors near people's homes was associated with decreased odds of being obese.

Low-income zip codes have 25 percent fewer chain supermarkets and 1.3 as many convenience stores compared to middle-income zip codes. ${ }^{33}$ Low-income neighborhoods have half as many supermarkets as the wealthiest neighborhoods and four times as many smaller grocery stores, according to an assessment of 685 urban and rural census tracts in three states. ${ }^{39}$

Other studies gather much more detailed data, conducting in-store surveys to assess the availability, variety, quality, and price of particular healthy items. Among these studies ${ }^{2,37,40}$, it was found that food stores in lower-income neighborhoods are less likely to stock healthy foods, offer lower quality items, and have higher prices compared to stores in higher-income communities.

\subsection{Proximity to Supermarket and Fruit and Vegetable Intake}

Supermarkets tend to offer the greatest variety of low-fat healthy options at the lowest cost. $^{2}$ In contrast, convenience stores often sell duly prepared, high-calorie foods and little fresh produce, at higher prices. ${ }^{41}$ Studies suggests that neighborhood residents with better access to supermarkets and other retail stores that provide access to healthful food products tend to have healthier food intakes. ${ }^{42-44}$ Proximity to a supermarket has been associated with higher fruit and vegetable intake and better diet quality among low-income households. ${ }^{43}$ Despite some inconsistencies, several studies ${ }^{5,45}$ have shown that better access to a supermarket is associated 
with reduced risk of obesity, whereas greater access to convenience stores is associated with increased risk for obesity. ${ }^{5,45}$

Five studies analyzed access to nearby supermarkets or large grocery stores that sell a wide variety of healthy foods in relation to consumption of fruits and vegetables, specific healthy foods (such as low-fat milk or high-fiber bread), or a healthy diet (measured by an index of diet quality). Almost all of these studies controlled for individual characteristics such as race and income and still found a relationship between access and healthy eating. Four of the studies found associations between supermarket access and healthy eating among adults ${ }^{4,43,44,46}$ and one had mixed results. ${ }^{47}$

Only one study examined access to food stores and eating behaviors of adolescent boys aged 10 to 14 and did not find a relationship between supermarket access and fruit and vegetable consumptions but did find that proximity of convenience stores was associated with reduced fruit and vegetable intake. ${ }^{48}$

\subsection{Summary}

Prevalence of childhood obesity is extremely high in West Virginia. Although the etiology of obesity is complex and multifactorial, socioeconomic status may contribute to weight status by influencing food choice. Increased local availability of low-cost healthy food options or a high quality neighborhood nutrition environment may be associated with healthier diets, and thus healthier weight outcomes in children. 


\subsection{Materials and Methods}

\subsection{Enumeration of Stores}

The Institutional Review Board (IRB) committee at West Virginia University approved the protocol for this study. The survey area was defined as Marshall and Monongalia Counties combined, of West Virginia. Areas of poverty were defined by poverty quartiles using Census tract data. Poverty data from the American Community Survey 2005-2009 was obtained from the American Fact Finder. ${ }^{49}$ Poverty quartiles were computed based on population for whom poverty status is determined at or below $100 \%$ of the poverty threshold by Census tract. Areas of lowest poverty had between $0 \%$ and $8.1 \%$ of the population living below the poverty threshold. The next lowest poverty quartile included $8.1 \%$ to $18.76 \%$ of the population living below the poverty threshold. The third quartile consisted of $18.76 \%$ to $26.61 \%$ of those living below the poverty threshold. Areas of highest poverty had between $26.61 \%$ and $100 \%$ of the population living below the poverty threshold.

A list of all retail food outlets, convenience stores, and department stores in the state of West Virginia defined as SIC codes beginning with 53, 54, and 58 was purchased from InfoUSA $^{50}$, a marketing list sales firm. The data included company name, location address, Standard Industrial Classification (SIC) codes, square footage, number of employees, and additional information. The SIC codes provide a description of the type of store (e.g., grocery, convenience, department). There were 83 grocery and convenience stores and 61 department/general stores located in Monongalia and Marshall Counties. Department/general stores were included in the enumeration to capture retailers in this category that also sell food, such as Target and Dollar General. Further elimination of department stores without retail food sales, such as furniture and clothing stores resulted in a list of 97 stores, 37 grocery, 46 
convenience, and 14 department stores. The list of grocery stores included stores also known as supermarkets.

\subsection{Assessment of Food Availability, Price, and Quality}

The Nutrition Environment Measures Survey (NEMS) measures the nutrition environment in defined geographic areas using data collected by trained raters. The NEMSStore (NEMS-S) audits the availability, price, and quality of specific healthy and regular options in stores. ${ }^{2}$ The surveys consist of 11 indicator food categories: milk, fruit, vegetables, ground beef, hot dogs, frozen dinners, baked goods, beverages (soda/juice), bread, baked chips, and cereal.

Store identification numbers were assigned following the NEMS 8-digit system as follows:

1. First two digits represent the defined area, where $01=$ Monongalia County and 05=Marshall County.

2. Third digit represents the type of food outlet, where $1=$ store and $2=$ restaurant.

3. Fifth and sixth digits represent the type of store, where $01=$ grocery, $02=$ convenience and $03=$ other .

4. Last three digits represent the individual ID number.

Raters were recruited from undergraduate classes in Animal and Nutritional Sciences at West Virginia University to complete the surveys. All raters were trained using the NEMS online training. Pencils, clipboards, and letters to store managers were provided to the raters. It was the raters' responsibility for locating all stores. Surveys were turned in and checked for completeness. Surveys regarded as incomplete were re-surveyed. Raters were asked to take notes of store name changes, errors in addresses, stores declined being surveyed, and stores that 
were out of business. This provided a list of stores to remove from the analysis (Table 1). A total of 79 stores remained for analysis (Table 2). Cardiff Teleform ${ }^{\circledR}$ document scanning application was used to scan and verify completed NEMS-S surveys. Responses were stored in a Microsoft $®$ Excel database for analysis.

\subsection{Reliability Testing}

Reliability of the surveys was tested using inter-rater and test-retest methods. Inter-rater reliability was tested by sending two raters to the same store at the same time on the same day to see if they received the same results. Test-retest reliability was tested by sending the same rater to the same store one week apart to see if the same results were achieved. The latter method assumes that store measures do not change within a week. Both methods were tested on $10 \%$ of the total stores surveyed. There was a 95.6\% agreement between the raters using the inter-rater reliability testing and a $91.2 \%$ agreement using the test-retest method.

\subsection{Comparison Items}

Comparison items are shown in Table 3. Using the data collected from the NEMS-S, an availability comparison was conducted between the healthy and regular food options. The availability indicator was assessed based on a yes/no rating. A cost comparison was also conducted between healthy and regular food options. Cost was assessed based on the posted non-sale prices for healthier versus regular options for comparable products. Specific prices for each measure are listed in Table 4. 


\subsection{Nutrition Environment Quality Scores}

A composite nutrition environment quality score was calculated for each store using three

dimensions (availability, quality, and price) as developed by Glanz et al. ${ }^{2}$ Availability scores assigned two points per indicator for the availability of healthier options, and an extra point for more varieties (e.g., two extra points for three or more varieties of lean meat). Price scores assigned two points for a lower priced healthier option and -1 point for a higher priced healthier option, and up to three points were assigned for having more produce of acceptable quality. The total score could range from -9 to 54 .

\subsection{BMI Percentiles and Measurement Scores}

In looking at the nutrition environment, it is important to also look at BMI in the study area and how the two might be related. The Coronary Artery Risk Detection in Appalachian Communities (CARDIAC) study records and examines cardiovascular disease (CVD) risk factors in West Virginia school children. ${ }^{51}$ Among the data collected annually are height and weight. In the 2009-2010 school year, this data was collected on 398, 329, and 203 kindergarten, second, and fifth graders, respectively, in Monongalia County and 185, 170, and 125 kindergarten, second, and fifth graders, respectively, in Marshall County. Height, weight, and age were used to compute BMI percentiles for each participant. There were 1,410 total students screened which represented $42.7 \%$ of the student population. Table 12 displays the demographic characteristics and weight status of CARDIAC participants screened during the 2009-2010 school year in Monongalia and Marshall Counties.

Parent surveys were sent to the homes of all the children screened inquiring about dietary habits, physical activity patterns, and parental height and weight among other health related 
factors. Of the 1,410 surveys sent, 235 were returned and considered complete which provided a completion rate of $16.7 \%$ (Table 13). These completed parent surveys represent $7.1 \%$ of the total population of kindergarten, second and fifth grade students in those counties.

A mean NEMS score was computed for each Census tract. This score represents the quality of the nutrition environment for each subject. The mean score at the tract level was attached to the case-level data.

\subsection{Statistical Analysis}

Availability of healthy items and cost comparisons between healthy and regular items were measured by store type and by area-level poverty quartile. Results are expressed as frequencies for availability and mean price \pm standard deviation for cost comparison.

Basic frequencies of availability were run for all variables in the dataset for measure1measure 11 by store type and by poverty quartile for the survey area. Dichotomous availability measures where $1=$ yes and $0=$ no were used for all measures. These values are shown in Tables 6 and 7. Significance for differences in availability of individual food items in Tables 6 and 7 was tested using Pearson's chi-square test. Fisher's exact test was used to further determine where the differences were among the store types and poverty quartiles with differences considered significant at $p<0.05$.

Mean prices of healthier options and regular options were computed for all comparison items (Table 3) by store type and by poverty quartile. These values are shown in Tables 8 and 9 . Differences in price of healthier options by store type and by poverty quartile in Tables 8 and 9 were tested using a two-sample t-test with equal variances with differences considered significant at $p<0.05$. 
Mean scores of the nutrition environment for each dimension (e.g., availability, price, quality) were calculated by store type and by poverty quartile for each county. Results are expressed as means $\underline{ \pm}$ standard deviation of the mean. Differences in NEMS score by store type and by poverty quartile were tested using a one-way ANOVA. Post-hoc multiple comparison tests were performed using Scheffe's test among the store types and among the poverty quartiles with differences considered significant at $p<0.05$. All statistical analyses were completed using Stata Statistical Software: Release $11 .^{52}$

A mean NEMS score was computed for each census tract by summing the individual store scores and dividing by the number of stores. The mean NEMS score for each census tract was entered into a multivariate analysis as an independent variable with other factors known to influence child BMI included as additional independent variables. These were, age of the child, family income, age, gender and BMI of parent respondent, parent and child dietary and physical activity indicators from the CARDIAC questionnaire, and neighborhood quality as represented by median household income for each tract. The outcome variable was BMI percentile.

The possibility of spatial autocorrelation, either in the form of a spatially lagged dependent variable or in the form of a spatial error process were tested using several Lagrange Multiplier tests that have been developed by Anselin et. al. ${ }^{53}$ Using a variety of spatial weight matrices (i.e. a matrix that relates observations in space to each other) we found no evidence of spatial autocorrelation and a standard logistic regression model was constructed. Outcome or dependent variable was dichotomous: coded 1 to indicate BMI at the 95th percentile or greater (obese) and 0 to indicate BMI less than the $95^{\text {th }}$ percentile (not obese). 


\subsection{Results}

\subsection{Population Characteristics}

The median household income of Marshall County is $\$ 34,330$ compared to $\$ 51,425$ nationwide. ${ }^{49}$ There are $14.0 \%$ of families and $17.6 \%$ of individuals living below the poverty level compared to $9.9 \%$ and $13.5 \%$ nationwide, respectively. ${ }^{49}$ The total population for the county is $33,205 .{ }^{49}$ Monongalia County has a median household income of $\$ 37,544 .{ }^{49}$ Of the 87,864 people living in Monongalia County, $9.7 \%$ of families and $21.4 \%$ of individuals are living below the poverty level. ${ }^{49}$ Because of the similarities between these two counties, they were combined together as one survey area. According to the Bureau of the Census, both counties are considered to be in metropolitan areas with a population fewer than $250,000 .{ }^{54}$ During the 2009-2010 school year, there were a total of 988 kindergarten, second and fifth graders in Marshall County and 2,307 in Monongalia County. Of the total students in the aforementioned grade levels in both counties combined, $89.4 \%$ were white and $47.0 \%$ were considered low SES. ${ }^{55}$

\subsection{Sample Characterstics}

From the CARDIAC screening data, 491 participants, or $34.8 \%$, of the children were overweight and 244, or 17.3\%, were obese (Table 12). The sample for the CARIDAC Parent Survey included 235 kindergarten, second, and fifth grade students in both counties combined. In the sample, $86.4 \%$ were white and $30.2 \%$ were considered low SES. Table 14 describes the student population with complete parent surveys compared to the total student population of the counties by grade as reported by the West Virginia Department of Education. ${ }^{55}$ There were significant differences at $p<0.05$ between the survey sample and the total student population in 
distribution by grade and SES, but not by race or gender. This indicates the sample does not accurately represent the student population in these counties with respect to SES or grade distribution.

\subsection{Availability of Healthier Options}

There were significant differences in the availability of healthier options between grocery and convenience stores and between grocery and other stores $(p<0.05)$ for the following measures: fruit, vegetables, lean ground beef, low-fat hot dogs, reduced calorie frozen dinners, low-fat baked goods, and 100\% whole grain bread (Table 6). There were also significant differences between convenience and other stores $(p<0.05)$ in the availability of low-fat baked goods, diet soda and low-fat chips. Availability of diet soda was significantly different between grocery stores and convenience stores. The results shown in Table 7 indicate that there was a significant difference in availability of low sugar cereal between poverty quartiles 2 and 3 and between quartiles 3 and 4 .

\subsection{Cost Comparison of Healthier vs. Regular Options}

There was a significant difference in price between healthy and regular options for lean ground beef $(\$ 0.75)$ in grocery stores, reduced calorie frozen dinners in all three types of stores (\$0.91, \$0.81, \$1.97, for grocery, convenience, and other stores, respectively) and 100\% whole grain bread in grocery and convenience stores (\$0.58 and \$0.61, respectively). Difference in price between healthy and regular options was also significant for lean ground beef in poverty quartiles 1,3 , and $4(\$ 0.90, \$ 0.83$, and $\$ 0.71$, respectively), reduced calorie frozen dinners in quartiles 1 and 4 (\$0.92 and \$1.06, respectively), and 100\% whole grain bread in quartiles 1,2 , 
and 3 (\$0.69, $\$ 0.70$, and $\$ 0.47$, respectively). The healthier options of ground beef and bread were more expensive while the healthier reduced calorie frozen dinners were cheaper than their regular counterparts. There were no significant differences in price among store type or among poverty quartiles.

\subsection{NEMS-S Scores}

Composite mean NEMS scores and standard deviations by store type are shown in Table 10. Composite mean NEMS scores and standard deviations by poverty quartile for the two counties are displayed in Table 11. Using the NEMS scoring system as a means of measuring differences, there were significant differences $(p<0.05)$ in availability, price, quality, and total points among store types. However, there were no significant differences in availability, price, quality, or total points among poverty quartiles.

\subsection{Association of Nutrition Environment with Obesity Prevalence}

The results of the logistic regression analysis used to calculate odds ratios for the prevalence of obesity associated with physical activity, parental weight, family income, and other known covariates are included in Table 15. Controlling for parent age and gender, child age and gender, area-level nutrition score and median household income, and reported frequency of fruit and/or vegetable and fast food intake, it was found that a child reported to get 30 minutes of moderate physical activity (PA) at least 6 days per week was $9 \%$ less likely to be obese than a child reported to get 30 minutes of moderate PA less than 6 days per week. A child with an overweight parent was 3.8 times more likely to be obese than a child with a normal weight 
parent. A child in a family with income less than $\$ 50,000$ per year was almost 3 times as likely to be obese as a child in a family with income $\$ 50,000$ or more. 


\subsection{Discussion}

In this sample, outlet-level nutrition quality varied by store type, but the nutrition environment within a Census tract did not vary significantly by tract-level poverty. Additionally, the quality of the nutrition environment in the Census tract of residence was not significantly associated with the prevalence of obesity in children in the survey area. Because convenience stores and general and department stores have lower availability of healthy foods compared to grocery stores, people who shop more frequently at these stores may be at higher risk of obesity. It is highly likely that where a person shops for food is a more substantial contributor to obesity than the quality of the community nutrition environment in the immediate area of residence defined by Census tract boundaries. Census boundaries are designed to measure areas for administrative purposes. They are not necessarily representative of neighborhood or community boundaries and likely do not delineate shopping areas for individuals. Since the availability of healthy food options in the immediate nutrition environment was not significantly associated with weight status, family food purchases were likely made beyond the boundaries of the Census tract. Other unmeasured factors that influence personal choice and behavior likely contribute. Walkability, determined by the availability of sidewalks and pedestrian crossings has been identified as an important area-level contributor to obesity. Access to bike paths, fast-food restaurants, playgrounds, and gym facilities in an area may also affect weight status.

According to the screening data from CARDIAC, $34.8 \%$ of children were overweight and $17.3 \%$ were obese. The obesity prevalence is consistent with national statistics ${ }^{7}$ and the overweight prevalence with state data as reported by Singh et al. ${ }^{11}$ In this study children who had an overweight/obese parent were much more likely to be obese. It is reasonable to conclude that parental behavior and the home nutrition environment contribute to obesity in addition to 
inheritable biological traits. The home nutrition environment is thought to be particularly important for young children because they are dependent on parents to purchase food. The availability of food in the home has a significant impact on intake in young children. ${ }^{56,57}$ Lack of regular physical activity was significantly associated with an increased likelihood of obesity. This finding is consistent with other studies indicating the importance of physical activity in maintenance of appropriate weight status in children. ${ }^{58-60}$

Children in families with an annual income less than $\$ 50,000$ were more likely to be obese. The association between weight status in children and SES has been inconsistent particularly among racial/ethnic and age groups. ${ }^{30}$ West Virginia has the second lowest median household income in the US after Mississippi. ${ }^{49}$ The median household income is $\$ 34,330$ in Marshall County and $\$ 37,544$ in Monongalia County compared to $\$ 51,425$ nationwide with very few racial differences (98.1\% white in Marshall County and 92.0\% white in Monongalia County), but a high prevalence of obesity. ${ }^{49}$ Additionally, the sample was limited to children ages 5- to 10-years old. Since these data are not confounded by race/ethnicity and a large variation in age, the association of childhood obesity with family SES is more clear. Energy dense foods are cheaper than foods with low energy density. ${ }^{61}$ Due to limited resources, low income families purchase foods that are high in energy density because they are less expensive. As a result, children in low-income families consume diets that are higher in energy density compared to children from more affluent families leading to excess weight gain and obesity. ${ }^{62}$ 


\subsection{Limitations}

There were some limitations in this study that need to be addressed. The sample of stores surveyed was very small. A larger number would result in less variation and more accurate measures. It is possible that important variables and measures were missed due to limitations inherent in a secondary analysis of an established database. We did not include any data on shopping behavior and as a result, the stores surveyed may not be representative of the stores where people shop. 


\subsection{Summary and Conclusion}

In Monongalia and Marshall Counties, the quality of the nutrition environment does not differ by area-level poverty. Healthy food options are not more available in areas of high poverty compared to areas of low poverty and the cost does not vary by area-level poverty. The quality of the nutrition environment in the two counties studied is not significantly associated with the prevalence of childhood obesity after controlling for individual- and area-level household income. 


\subsection{References}

1. Menifield C, Doty N, Fletcher A. Obesity in America. ABNF 2008;19:83-88.

2. Glanz K, Sallis JF, Saelens BE, Frank LD et al. Nutrition Environment Measures Survey in Stores (NEMS-S): development and evaluation. Am J Prev Med 2007;32(4):282-289.

3. Spence JC, Cutumisu N, Edwards J, Raine KD, Smoyer-Tomic K. Relation between local food environments and obesity among adults. BMC Public Health 2009;9:192.

4. Morland K, Wing S, Diez-Roux A. The contextual effect of the local food environment on resident's diet: the Atherosclerosis Risk in Communities Study. Am J Public Health 2002;92:1761-67.

5. Powell L, Auld C, Chaloupka F, O'Malley P, Johnston L. Associations between access to food stores and adolescent body mass index. Am J Prev Med 2007;33:S301-S307.

6. Drewnowski A, Darmon N. Food choices and diet costs: an economic analysis. J Nutr 2005;135:900-904.

7. Ogden C, Carroll M, Curtin L, et al. Prevalence of overweight and obesity in the United States, 1999-2004. JAMA 2006;295:1549-1555.

8. Division of Nutrition, Physical Activity and Obesity, National Center for Chronic Disease Prevention and Health Promotion. Defining Childhood Overweight and Obesity; Atlanta, GA: US Department of Health and Human Services; 2009. http://www.cdc.gov/obesity/childhood/defining.html. Accessed November 20, 2010.

9. Centers for Disease Control and Prevention (CDC). Obesity prevalence among lowincome, preschool-aged children - United States, 1998-2008. MMWR Morb Mortal Wkly Rep 2009;58:769-773.

10. Flegal KM, Ogden CL, Yanovski JA, Freedman DS, Shepherd JA, Graubard BI, Borrud LG. High adiposity and high body mass index-for-age in US children and adolescents overall and by race-ethnic group. Am J Clin Nutr 2010;91:1020-6.

11. Singh GK, Kogan MD, van Dyck PC. Changes in state-specific childhood obesity and overweight prevalence in the United States from 2003 to 2007. Arch Pediatr Adolesc Med 2010;164:598-607.

12. Nielsen SJ, Siega-Riz AM, Popkin BM. Trends in food locations and sources among adolescents and young adults. Prev Med 2002;35:107-13.

13. Pesa JA, Turner LW. Fruit and vegetable intake and weight-control behaviors among U.S. youth. Am J Health Behav 2001;25:3-9.

14. Epstein L, Gordy CC, Raynor HA et al. Increasing fruit and vegetable intake and decreasing fat and sugar intake in families at risk for childhood obesity. Obes Res 2001;9:171-178.

15. Ludwig DS, Peterson KE, Gortmaker SL. Relation between consumption of sugarsweetened drink and childhood obesity: A prospective observational analysis. Lancet 2001;357:505-508.

16. French S, Story M, Jeffery RW. Environmental influences on eating and physical activity. Annu Rev Public Health 2001;22:309-335.

17. Young LR, Nestle M. The contribution of expanding portion sizes to the US obesity epidemic. Am J Public Health 2002;92:246-249.

18. National Center for Health Statistics. Health, United States, 2008 with Special Feature on the Health of Young Adults. Hyattsville, MD: US Department of Health and Human Services; 2009. 
19. National Center for Health Statistics. The National Health and Nutrition Examination Survey (NHANES), 2001-2006 Public Use Data Files. Hyattsville, MD: US Department of Health and Human Services; 2007.

http://www.cdc.gov/nchs/nhanes/nhanes_questionnaires.htm. Accessed February 28, 2011.

20. Bowman SA, Gortmaker SL, Ebbeling CB, Pereira MA, Ludwig DS. Effects of fast-food consumption on energy intake and diet quality among children in a national household survey. Pediatrics 2004;113:112-8.

21. Bray GA, Popkin BM. Dietary fat intake does affect obesity! Am J Clin Nutr 1998;68:1157-73.

22. Lin BH, Morrison RM. Higher fruit consumption linked with lower body mass index. Food Review 2002;25(3):28-32.

23. Reilly JJ, McDowell ZC. Physical activity interventions in the prevention and treatment of childhood obesity. Proc Nutr Soc 2003;62:611-9.

24. Robinson TN. Reducing children's TV viewing to prevent obesity: randomized controlled trial. JAMA 1999;282:1561-7.

25. Mutunga M, Gallagher A, Boreham C, et al. Socioeconomic differences in risk factors for obesity in adolescents in Northern Ireland. Int J Pediatr Obes 2006;1:114-119.

26. Davison KK, Birch LL. Obesigenic families: parents' physical activity and dietary intake patterns predict girls' risk of overweight. Int J Obes Relat Metab Disord 2002;26:1186 93.

27. Whitaker RC, Wright JA, Pepe MS, Seidel KD, Dietz WH. Predicting obesity in young adulthood from childhood and parental obesity. New Engl J Med 1997;337:869-873.

28. Maes HH, Neale MC, Eaves LJ. Genetic and environmental factors in relative body weight and human adiposity. Behavior Genetics 1997;27(4):325-376.

29. Stunkard AJ, Harris JR, Pedersen NL, McClearn GE. The body-mass index of twins who have been reared apart. New England Journal of Medicine 1990; 322(21):1483-1490.

30. Wang Y, Zhang Q. Are American children and adolescents of low socioeconomic status at increased risk of obesity? Changes in the association between overweight and family income between 1971 and 2002. Am J Clin Nutr 2006;84:707-16.

31. Vieweg VR, Johnston CH, Lanier JO, Fernandez A, Pandurangi AK. Correlation between high risk obesity groups and low socioeconomic status in school children. South Med J 2007;100:8-13.

32. Wardle J, Walker J, Jarvis MJ. Sex differences in the association of socioeconomic status with obesity. Am J Public Health 2002;92:1299-1304.

33. Powell L, Slater S, Mirtcheva D, Bao Y, Chaloupka F. Food store availability and neighborhood characteristics in the United States. Prev Med 2007;44:189-95.

34. Morton L, Blanchard T. Starved for access: life in rural America's food deserts. Rural Realities 2007. Available at www.ruralsociology.org/pubs/ruralrealities/issue4.html.

35. Drewnowski A. Obesity, diets, and social inequalities. Nutr Rev 2009;67:36-39.

36. Swinburn B, Caterson I, Seidall J, James W. Diet, nutrition and prevention of excess weight gain and obesity. Public Health Nutr 2004;7:123-46.

37. Chung C, Myers SL. Do the poor pay more for food? An analysis of grocery store availability and food price disparities. J Cons Aff 1999;33:276-96.

38. Morland K, Wing S, Diez-Roux A, Poole C. Neighborhood characteristics associated with the location of food stores and food services places. Am J Prev Med 2002;22:23-29. 
39. Moore L, Roux A. Associations of neighborhood characteristics with the location and type of food stores. Am J Public Health 2006;96:325-331.

40. Bodor JN, Rose D, Farley TA, Swalm C, Scott SK. Neighborhood fruit and vegetable availability and consumption: the role of small food stores in an urban environment. Public Health Nutr 2008;11:413-420.

41. Zenk SN, Schulz AJ, Israel BA et al. Fruit and vegetable access differs by community racial composition and socioeconomic position in Detroit, Michigan. Ethn Dis 2006;16:275-80.

42. Larson NI, Story MT, Nelson MC. Neighborhood environments: disparities in access to healthy foods in the U.S. Am J Prev Med 2009;36:74-81.

43. Rose D, Richards R. Food store access and household fruit and vegetable use among participants in the US Food Stamp Program. Public Health Nutr 2004;7:1081-88.

44. Laraia BA, Siega-Riz AM, Kaufman JS, Jones, SJ. Proximity of supermarkets is positively associated with diet quality index for pregnancy. Prev Med 2004;39:869-75.

45. Morland K, Diez-Roux AV, Wing S. Supermarkets, other food stores, and obesity: the atherosclerosis risk in communities study. Am J Prev Med 2006;30:333-9.

46. Zenk SN, Schulz AJ, Hollis-Neely T et al. Fruit and vegetable intake in African Americans - Income and store characteristics. Am J Prev Med 2005;29:1-9.

47. Wang M, Kim S, Gonzalez A, MacLeod K, Winkleby M. Socioeconomic and foodrelated physical characteristics of the neighborhood environment are associated with body mass index. J Epidemiol Community Health 2007;61:491-498.

48. Jago R, Baranowski T, Baranowski J, Cullen K, Thompson D. Distance to food stores and adolescent male fruit and vegetable consumption: mediation effects. Int J Behav Nutr Phys Act 2007;4:4-35. Available at http://www.ijbnpa.org/content/4/1/35.

49. U.S. Census Bureau. American Fact Finder. http://factfinder.census.gov/home/saff/main.html?_lang=en Accessed March 28, 2011.

50. InfoUSA.com, Inc. Omaha, NE.

51. Neal WA, Demerath E, Gonzales E et al. Coronary Artery Risk Detection in Appalachian Communities (CARDIAC): preliminary findings. West Virginia Medical Journal 2001;97.2:102-105.

52. StataCorp. College Station, TX.

53. Anselin, L, Anil KB, Raymond JF, Mann JY. Simple diagnostic tests for spatial dependence. Regional Science and Urban Economics 1996;26(1):77-104.

54. Economic Research Service. Rural-Urban Continuum Codes. Washington, DC: US Department of Agriculture; 2003. http://www.ers.usda.gov/Data/RuralUrbanContinuumCodes/ Accessed April 12, 2011.

55. West Virginia Department of Education. http://wvde.state.wv.us/ Accessed April 15, 2011.

56. Rosenkranz RR, Dzewaltowski DA. Model of the home food environment pertaining to childhood obesity. Nutr Rev 2008;66(3):123-140.

57. Spurrier NJ, Magarey AA, Golley R, Curnow F, Sawyer MG. Relationships between the home environment and physical activity and dietary patterns of preschool children: a cross-sectional study. Int J Behav Nutr Phys Act 2008;5:31.

58. Anderson RE, Crespo CJ, Bartlett SJ, Cheskin LJ, Pratt M. Relationship of physical activity and television watching with body weight and level of fatness among children. JAMA 1998;279(12):938-942. 
59. Saris WHM, Blair SN, Van Baak MA, et al. How much physical activity is enough to prevent unhealthy weight gain? Outcome of the IASO $1^{\text {st }}$ Stock Conference and consensus statement. Obes Rev 2003;4(2):101-114.

60. Fogelholm M, Kukkonen-Harjula K. Does physical activity prevent weight gain-a systematic review. Obes Rev 2000;1(2):95-111.

61. Andrieu E, Darmon N, Drewnowski A. Low-cost diets: more energy, fewer nutrients. Eur J Clin Nutr 2006;60(3):434-436.

62. Drewnowski A, Specter SE. Poverty and obesity: the role of energy density and energy costs. Am J Clin Nutr 2004;79(1):6-16. 


\section{Tables}

Table 1. Stores Removed from Analysis

\begin{tabular}{ll}
\hline Store ID & Reason \\
\hline $01-1-02-010$ & Could not locate \\
$01-1-02-040$ & Declined being surveyed \\
$01-1-02-020$ & Previously surveyed under 01-1-02-009 \\
$01-1-02-027$ & Address did not exist \\
$01-1-02-031$ & Previously surveyed under 01-1-02-022 \\
$01-1-02-025$ & Offered none of the measures (vending machine) \\
$01-1-01-020$ & Keg store \\
$01-1-01-022$ & Out of business \\
$01-1-01-024$ & Out of business \\
$01-1-01-027$ & Specialty store (Asian foods only) \\
$01-1-01-026$ & Could not locate \\
$01-1-03-011$ & Offered none of the measures \\
$01-1-03-005$ & Declined being surveying \\
$05-1-01-012$ & Bakery \\
$05-1-01-009$ & Offered none of the measures (Poker store) \\
$05-1-02-008$ & Could not locate \\
$05-1-02-009$ & Could not locate \\
$05-1-01-010$ & Could not locate \\
\hline
\end{tabular}

Table 2. Number and Type of Stores Surveyed by County

\begin{tabular}{lcccc}
\hline & \multicolumn{3}{c}{ Store Type } & \\
\cline { 2 - 4 } County & Grocery & Convenience & Others & Total \\
\hline Marshall & 8 & 9 & 3 & 20 \\
Monongalia & 21 & 29 & 9 & 59 \\
Total & 29 & 38 & 12 & $\mathbf{7 9}$ \\
\hline
\end{tabular}


Table 3. Comparison Items

\begin{tabular}{|c|c|c|}
\hline Measure & Regular Food & Healthier Option \\
\hline Measure 1 & Whole milk & Skim milk \\
\hline Measure 4 & $\begin{array}{l}\text { Standard ground beef, } 80 \% \text { lean, } 20 \% \\
\text { fat }\end{array}$ & Lean ground beef, $90 \%$ lean, $10 \%$ fat \\
\hline Measure 5 & $\begin{array}{l}\text { Oscar Mayer Wieners } \\
\text { (turkey/pork/chicken), } 12 \mathrm{~g} \mathrm{fat}\end{array}$ & $\begin{array}{l}\text { Oscar Mayer } 98 \% \text { Fat Free Wieners } \\
\text { (turkey/beef), } 0.5 \mathrm{~g} \text { fat }\end{array}$ \\
\hline \multirow[t]{3}{*}{ Measure 6} & Stouffer's Lasagna, $\geq 10 \mathrm{~g}$ fat $/$ serving & $\begin{array}{l}\text { Lean Cuisine Lasagna, } \leq 9 \mathrm{~g} \\
\text { fat } / \text { serving }\end{array}$ \\
\hline & $\begin{array}{l}\text { Stouffer's Roasted Turkey Breast, } \geq 10 \\
\text { g fat/serving }\end{array}$ & $\begin{array}{l}\text { Lean Cuisine Roasted Turkey Breast, } \\
\leq 9 \mathrm{~g} \text { fat/serving }\end{array}$ \\
\hline & Stouffer's Meatloaf, $\geq 10 \mathrm{~g}$ fat/serving & $\begin{array}{l}\text { Lean Cuisine Meatloaf, } \leq 9 \mathrm{~g} \\
\text { fat/serving }\end{array}$ \\
\hline Measure 7 & $\begin{array}{l}\text { Regular muffin, } \geq 4 \mathrm{~g} \text { fat } / \text { serving or } 400 \\
\text { Kcal/serving }\end{array}$ & Bagel, $\leq 3 \mathrm{~g}$ fat $/$ serving \\
\hline \multirow[t]{2}{*}{ Measure 8} & Coke & Diet Coke \\
\hline & Juice drink & $100 \%$ juice \\
\hline Measure 9 & White bread, made with refined flour & $\begin{array}{l}\text { Whole grain bread, } 100 \% \text { whole wheat } \\
\text { bread and whole grain bread }\end{array}$ \\
\hline Measure 10 & Lays Potato Chips Classic & $\begin{array}{l}\text { Baked Lays Potato Chips, } \leq 3 \mathrm{~g} \text { fat } / 1 \\
\text { oz. serving }\end{array}$ \\
\hline Measure 11 & $\begin{array}{l}\text { Cheerios Flavored cereal, } \geq 7 \mathrm{~g} \\
\text { sugar/serving }\end{array}$ & $\begin{array}{l}\text { Cheerios Plain cereal, }<7 \mathrm{~g} \\
\text { sugar/serving }\end{array}$ \\
\hline
\end{tabular}


Table 4. Price Measurements

\begin{tabular}{ll}
\hline Measure & Price Measurement \\
Measure 1: Milk & $\begin{array}{l}\text { price of half gallons } \\
\text { new per unit or per lb price variables } \\
\text { (whichever is more common for the specific } \\
\text { fruit) }\end{array}$ \\
Measure 3: Vegetables & $\begin{array}{l}\text { new per unit or per lb price variables } \\
\text { (whichever is more common for the specific } \\
\text { vegetable) }\end{array}$ \\
Measure 4: Ground Beef & price/lb \\
Measure 5: Hot Dogs & price/package \\
Measure 6: Frozen Dinners & price/package \\
Measure 7: Baked Goods & price/piece \\
Measure 8: Beverage & price/ounce \\
Measure 9: Bread & price/loaf \\
Measure 10: Baked Chips & price/oz \\
Measure 11: Cereal & price/box \\
\hline
\end{tabular}

Table 5. Number of Stores by Poverty Quartile

\begin{tabular}{llll}
\hline Poverty Quartiles & Frequency & Percent & Cumulative \\
\hline 1 & 18 & 22.8 & 22.8 \\
2 & 21 & 26.6 & 49.4 \\
3 & 17 & 21.5 & 70.9 \\
4 & 23 & 29.1 & 100.0 \\
\hline Total & 79 & 100.0 & \\
\hline
\end{tabular}


Table 6. Availability of Healthier Options by Store Type

\begin{tabular}{lccc}
\hline Type of Food \& Availability & $\mathbf{a}$ & $\mathbf{b}$ & $\mathbf{c}$ \\
\cline { 2 - 4 } & $\begin{array}{c}\text { Grocery } \\
\text { Stores }(\mathrm{n}=29)\end{array}$ & $\begin{array}{c}\text { Convenience } \\
\text { Stores } \\
(\mathrm{n}=38)\end{array}$ & $\begin{array}{c}\text { Other Stores } \\
(\mathrm{n}=12)\end{array}$ \\
\hline
\end{tabular}

Skim/low-fat milk

\begin{tabular}{|c|c|c|c|c|}
\hline Available & 25 & 33 & 9 & \\
\hline Not Available & 4 & 5 & 3 & \\
\hline \multicolumn{5}{|c|}{ Any fruit } \\
\hline Available & 23 & 6 & 1 & $\mathrm{ab}, \mathrm{ac}$ \\
\hline Not Available & 6 & 32 & 11 & \\
\hline \multicolumn{5}{|c|}{ Any vegetables } \\
\hline Available & 21 & 5 & 1 & $a b, a c$ \\
\hline Not Available & 8 & 33 & 11 & \\
\hline \multicolumn{5}{|c|}{ Lean ground beef } \\
\hline Available & 14 & 0 & 1 & $\mathrm{ab}, \mathrm{ac}$ \\
\hline Not Available & 15 & 38 & 11 & \\
\hline \multicolumn{5}{|c|}{ Low-fat hot dogs } \\
\hline Available & 14 & 0 & 1 & $\mathrm{ab}, \mathrm{ac}$ \\
\hline Not Available & 15 & 38 & 11 & \\
\hline \multicolumn{5}{|c|}{ Reduced calorie frozen dinners } \\
\hline Available & 17 & 10 & 1 & $a b, a c$ \\
\hline Not Available & 12 & 28 & 11 & \\
\hline \multicolumn{5}{|c|}{ Low-fat baked goods } \\
\hline Available & 20 & 0 & 3 & $a b, a c, b c$ \\
\hline Not Available & 9 & 38 & 9 & \\
\hline \multicolumn{5}{|c|}{ Diet Soda } \\
\hline Available & 25 & 38 & 9 & $a b, b c$ \\
\hline Not Available & 4 & 0 & 3 & \\
\hline \multicolumn{5}{|c|}{$100 \%$ fruit juice } \\
\hline Available & 24 & 36 & 11 & \\
\hline Not Available & 5 & 2 & 1 & \\
\hline \multicolumn{5}{|c|}{$100 \%$ whole grain bread } \\
\hline Available & 23 & 14 & 1 & $\mathrm{ab}, \mathrm{ac}$ \\
\hline Not Available & 6 & 24 & 11 & \\
\hline \multicolumn{5}{|c|}{ Baked/low-fat chips } \\
\hline Available & 18 & 31 & 4 & $\mathrm{bc}$ \\
\hline
\end{tabular}


Not Available

11

Low sugar cereal

\begin{tabular}{lccc}
\hline Available & 26 & 27 & 11 \\
Not Available & 3 & 11 & 1 \\
\hline *Significant differences among groups where $0<0.05$ &
\end{tabular}

*Significant differences among groups where $\mathrm{p}<0.05$

Fisher's exact 
Table 7. Availability of Healthier Options by Percent Poverty Threshold

\begin{tabular}{|c|c|c|c|c|c|}
\hline \multirow{2}{*}{$\begin{array}{l}\text { Type of Food \& } \\
\text { Availability }\end{array}$} & \multirow{2}{*}{$\begin{array}{c}\text { a } \\
\text { Below 25 }^{\text {th }} \\
\text { Percentile } \\
\quad(n=18)\end{array}$} & \multirow{2}{*}{ 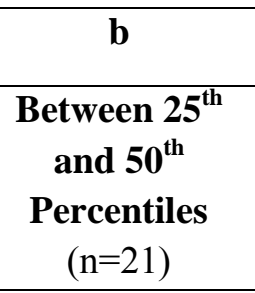 } & \multirow{2}{*}{$\begin{array}{c}\text { c } \\
\text { Between 50 }^{\text {th }} \\
\text { and } 75^{\text {th }} \\
\text { Percentiles } \\
(\mathrm{n}=17) \\
\end{array}$} & \multirow{2}{*}{$\begin{array}{c}\text { d } \\
\text { Above } 75^{\text {th }} \\
\text { Percentile } \\
\quad(n=23)\end{array}$} & \multirow[t]{2}{*}{ *Significance } \\
\hline & & & & & \\
\hline \multicolumn{6}{|c|}{ Skim/low-fat milk } \\
\hline Available & 16 & 16 & 16 & 19 & \\
\hline Not Available & 2 & 5 & 1 & 4 & \\
\hline \multicolumn{6}{|c|}{ Any fruit } \\
\hline Available & 10 & 6 & 6 & 8 & \\
\hline Not Available & 8 & 15 & 11 & 15 & \\
\hline \multicolumn{6}{|c|}{ Any vegetables } \\
\hline Available & 8 & 6 & 5 & 8 & \\
\hline Not Available & 10 & 15 & 12 & 15 & \\
\hline \multicolumn{6}{|c|}{ Lean ground beef } \\
\hline Available & 6 & 3 & 2 & 4 & \\
\hline Not Available & 12 & 18 & 15 & 19 & \\
\hline \multicolumn{6}{|c|}{ Low-fat hot dogs } \\
\hline Available & 5 & 3 & 4 & 3 & \\
\hline Not Available & 13 & 18 & 13 & 20 & \\
\hline \multicolumn{6}{|c|}{ Reduced calorie frozen dinners } \\
\hline Available & 8 & 6 & 6 & 8 & \\
\hline Not Available & 10 & 15 & 11 & 15 & \\
\hline \multicolumn{6}{|c|}{ Low-fat baked goods } \\
\hline Available & 7 & 6 & 5 & 5 & \\
\hline Not Available & 11 & 15 & 12 & 18 & \\
\hline \multicolumn{6}{|c|}{ Diet Soda } \\
\hline Available & 16 & 19 & 16 & 21 & \\
\hline Not Available & 2 & 2 & 1 & 2 & \\
\hline \multicolumn{6}{|c|}{$100 \%$ fruit juice } \\
\hline Available & 16 & 18 & 17 & 20 & \\
\hline Not Available & 2 & 3 & 0 & 3 & \\
\hline \multicolumn{6}{|c|}{$100 \%$ whole grain bread } \\
\hline Available & 10 & 10 & 8 & 10 & \\
\hline Not Available & 8 & 11 & 9 & 13 & \\
\hline
\end{tabular}

Baked/low-fat chips 


\begin{tabular}{lrrrrr}
\hline Available & 12 & 13 & 9 & 19 & \\
Not Available & 6 & 8 & 8 & 4 & \\
\hline \multicolumn{7}{c}{ Low sugar cereal } \\
Available & 16 & 14 & 17 & 17 & $\mathrm{bc}, \mathrm{cd}$ \\
Not Available & 2 & 7 & 0 & 6 & \\
\hline
\end{tabular}

*Significant differences among groups where $\mathrm{p}<0.05$

Fisher's exact 
Table 8. Cost Comparison of Healthier vs. Regular Options by Store Type

\begin{tabular}{|c|c|c|c|c|}
\hline \multirow[t]{2}{*}{ Food Item } & \multirow{2}{*}{$\begin{array}{c}\mathbf{a} \\
\begin{array}{c}\text { Grocery Stores } \\
(\mathrm{n}=29)\end{array}\end{array}$} & $\mathbf{b}$ & \multirow{2}{*}{$\begin{array}{c}\mathbf{c} \\
\begin{array}{c}\text { Other Stores } \\
(\mathrm{n}=12)\end{array}\end{array}$} & \multirow[t]{2}{*}{ *Significance } \\
\hline & & $\begin{array}{c}\text { Convenience } \\
\text { Stores } \\
(\mathrm{n}=38) \\
\end{array}$ & & \\
\hline \multicolumn{5}{|c|}{ Milk } \\
\hline Skim/Low-Fat & $2.62 \pm 1.62$ & $2.73 \pm 0.91$ & $2.83 \pm 0.29$ & \\
\hline Whole & $2.56 \pm 1.32$ & $2.80 \pm 0.97$ & $2.90 \pm 0.24$ & \\
\hline \multicolumn{5}{|c|}{ Ground Beef } \\
\hline Lean & $3.59 \pm 0.41$ & & $4.15 \pm 0$ & $\mathrm{a}$ \\
\hline Standard & $2.84 \pm 0.39$ & & $2.83 \pm 0.04$ & \\
\hline \multicolumn{5}{|c|}{ Hot Dogs } \\
\hline Fat Free & $3.91 \pm 1.21$ & & & \\
\hline Regular & $3.25 \pm 0.81$ & $3.01 \pm 1.69$ & $3.99 \pm 0.69$ & \\
\hline \multicolumn{5}{|c|}{ Frozen Dinners } \\
\hline Reduced Calorie & $2.29 \pm 0.90$ & $3.03 \pm 0.81$ & $1.98 \pm 1.39$ & $a b c$ \\
\hline Regular & $3.20 \pm 1.60$ & $3.84 \pm 0.66$ & $3.95 \pm 0$ & \\
\hline \multicolumn{5}{|c|}{ Baked Goods } \\
\hline Low-fat Bagel & $2.20 \pm 1.14$ & & 4.88 & \\
\hline Muffin & $2.49+1.44$ & $1.32+0.30$ & $2.22+1.72$ & \\
\hline \multicolumn{5}{|c|}{ Soda } \\
\hline Diet Coke & $4.64 \pm 1.04$ & $1.51 \pm 0.22$ & $3.06 \pm 0.83$ & \\
\hline Coke & $4.65 \pm 1.04$ & $1.51 \pm 0.22$ & $3.06 \pm 0.83$ & \\
\hline \multicolumn{5}{|c|}{ Juice } \\
\hline $\begin{array}{l}\text { 100\% Fruit Juice } \\
\text { Juice Drink }\end{array}$ & $\begin{array}{l}2.82 \pm 0.37 \\
2.16+0.68\end{array}$ & $\begin{array}{l}1.68 \pm 0.15 \\
1.74+0.43\end{array}$ & $\begin{array}{l}3.00 \pm 1.17 \\
2.40+1.08\end{array}$ & \\
\hline \multicolumn{5}{|c|}{ Bread } \\
\hline $100 \%$ Whole Grain & $2.59 \pm 1.17$ & $2.72 \pm 0.10$ & 4.48 & $\mathrm{ab}$ \\
\hline White & $2.01 \pm 0.54$ & $2.11 \pm 0.41$ & $1.78 \pm 0.55$ & \\
\hline \multicolumn{5}{|c|}{ Chips } \\
\hline Baked Lays & $3.28 \pm 0.97$ & $1.18 \pm 0.70$ & $3.12 \pm 2.52$ & \\
\hline Lays Classic & $2.89 \pm 0.95$ & $1.15 \pm 0.68$ & $3.50 \pm 1.02$ & \\
\hline \multicolumn{5}{|c|}{ Cereal } \\
\hline Cheerios Plain & $3.46 \pm 1.49$ & $4.09 \pm 1.84$ & $2.98 \pm 1.08$ & \\
\hline Cheerios Flavored & $3.37 \pm 1.02$ & $4.02 \pm 2.00$ & $3.09 \pm 1.41$ & \\
\hline
\end{tabular}

*Significance at $\mathrm{p}<0.05$ 
Table 9. Cost Comparison of Healthier vs. Regular Options by Percent Poverty Threshold

\begin{tabular}{|c|c|c|c|c|c|}
\hline \multirow[t]{2}{*}{ Food Item } & $\mathbf{a}$ & b & c & d & *Significance \\
\hline & $\begin{array}{c}\text { Below 25 }{ }^{\text {th }} \\
\text { Percentile } \\
(n=18)\end{array}$ & 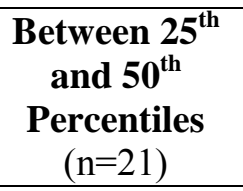 & $\begin{array}{c}\text { Between 50 }^{\text {th }} \\
\text { and 75 } \\
\text { Percentiles } \\
(\mathrm{n}=17)\end{array}$ & $\begin{array}{c}\text { Above }_{\mathbf{7 5}}^{\text {th }} \\
\text { Percentile } \\
(\mathrm{n}=23)\end{array}$ & \\
\hline \multicolumn{6}{|c|}{ Milk } \\
\hline Skim/Low-Fat & $2.70 \pm 1.49$ & $2.93 \pm 1.30$ & $2.58 \pm 0.50$ & $2.60 \pm 1.18$ & \\
\hline Whole & $2.42 \pm 0.49$ & $3.02 \pm 1.40$ & $2.59 \pm 0.48$ & $2.77 \pm 1.35$ & \\
\hline \multicolumn{6}{|c|}{ Ground Beef } \\
\hline Lean & $3.63 \pm 0.32$ & $3.76 \pm 0.83$ & $3.68 \pm 0.13$ & $3.51 \pm 0.37$ & acd \\
\hline Standard & $2.73+0.49$ & $2.96 \pm 0.23$ & $2.85 \pm 0.31$ & $2.80 \pm 0.38$ & \\
\hline \multicolumn{6}{|c|}{ Hot Dogs } \\
\hline Fat Free & $4.09 \pm 1.14$ & $4.49 \pm 0.51$ & $2.83 \pm 1.75$ & $4.13 \pm 1.09$ & \\
\hline Regular & $3.31 \pm 1.19$ & $3.32 \pm 1.33$ & $3.83 \pm 1.03$ & $2.47 \pm 1.21$ & \\
\hline \multicolumn{6}{|c|}{ Frozen Dinners } \\
\hline Reduced Calorie & $2.06 \pm 0.61$ & $2.61 \pm 1.21$ & $3.07 \pm 1.34$ & $2.21 \pm 0.56$ & ad \\
\hline \multicolumn{6}{|c|}{ Baked Goods } \\
\hline Low-Fat Bagel & $2.62 \pm 1.36$ & $1.67 \pm 1.44$ & $2.10 \pm 0.78$ & $2.86 \pm 1.31$ & \\
\hline Muffin & $2.21 \pm 1.66$ & $1.64 \pm 0.79$ & $1.79 \pm 1.19$ & $1.95 \pm 1.22$ & \\
\hline \multicolumn{6}{|c|}{ Soda } \\
\hline Diet Coke & $3.29 \pm 1.62$ & $2.84 \pm 1.59$ & $2.92 \pm 1.64$ & $2.25 \pm 1.37$ & \\
\hline Coke & $1.57 \pm 0.08$ & $1.56 \pm 0.10$ & $1.49 \pm 0.24$ & $1.47 \pm 0.30$ & \\
\hline \multicolumn{6}{|c|}{ Juice } \\
\hline 100\% Fruit Juice & $1.72 \pm 0.08$ & $1.63 \pm 0.18$ & $1.68 \pm 0.18$ & $1.69 \pm 0.15$ & \\
\hline Juice Drink & $1.69 \pm 0.14$ & \multicolumn{2}{|c|}{ Bread } & & \\
\hline 100\% Whole & & & & & $a b c$ \\
\hline Grain & $2.84 \pm 0.76$ & $2.62 \pm 0.40$ & $2.39 \pm 0.33$ & $2.83 \pm 1.68$ & \\
\hline White & $2.15 \pm 0.54$ & $1.92 \pm 0.48$ & $1.92 \pm 0.51$ & $2.09 \pm 0.43$ & \\
\hline \multicolumn{6}{|c|}{ Chips } \\
\hline Baked Lays & $2.99 \pm 1.61$ & $1.91 \pm 1.44$ & $2.01 \pm 1.41$ & $1.47 \pm 0.99$ & \\
\hline Lays Classic & $2.61+1.49$ & $2.22+1.42$ & $2.33 \pm 1.12$ & $1.41 \pm 0.81$ & \\
\hline \multicolumn{6}{|c|}{ Cereal } \\
\hline $\begin{array}{l}\text { Cheerios Plain } \\
\text { Cheerios }\end{array}$ & $3.44 \pm 1.56$ & $3.79 \pm 1.40$ & $3.16 \pm 1.34$ & $4.21 \pm 2.03$ & \\
\hline Flavored & $3.59 \pm 1.81$ & $3.49 \pm 1.55$ & $3.39 \pm 1.54$ & $4.04 \pm 1.69$ & \\
\hline
\end{tabular}

*Significance at $\mathrm{p}<0.05$ 
Table 10. NEMS Composite Mean Scores for Healthy Nutrition Environments in Stores

a

c

*Significance

\begin{tabular}{ccc}
\hline $\begin{array}{c}\text { Grocery Stores } \\
(\mathrm{n}=29)\end{array}$ & $\begin{array}{c}\text { Convenience Stores } \\
(\mathrm{n}=38)\end{array}$ & $\begin{array}{c}\text { Other Stores } \\
(\mathrm{n}=12)\end{array}$
\end{tabular}

\begin{tabular}{lrrrr}
\hline Availability & $17.9 \pm 9.4$ & $8.2 \pm 3.0$ & $7.3 \pm 5.4$ & $\mathrm{ab}, \mathrm{ac}$ \\
Price & $2.3 \pm 2.2$ & $3.5 \pm 1.7$ & $2.5 \pm 1.4$ & $\mathrm{ab}$ \\
Quality & $4.5 \pm 2.3$ & $0.6 \pm 1.6$ & $0.5 \pm 1.7$ & $\mathrm{ab}, \mathrm{ac}$ \\
Total ${ }^{\dagger}$ & $24.7 \pm 11.9$ & $12.3 \pm 4.7$ & $10.3 \pm 8.1$ & $\mathrm{ab}, \mathrm{ac}$
\end{tabular}

†Maximum possible score is 54

*Significant differences among groups where $p<0.05$

One-way ANOVA Scheffe's test. Response variable=scores (avail, price, quality, total). Factor variable $=$ store type.

Table 11. NEMS Composite Mean Scores for Stores by Census Tract Poverty Level

\begin{tabular}{|c|c|c|c|c|c|}
\hline & $\mathbf{a}$ & b & c & d & *Significance \\
\hline & Q1 $(n=18)$ & $\mathbf{Q 2}(\mathrm{n}=21)$ & Q3 $(n=17)$ & Q4 $(n=23)$ & \\
\hline Availability & $20.2 \pm 12.5$ & $14.8 \pm 10.6$ & $16.1 \pm 9.3$ & $15.7 \pm 9.5$ & \\
\hline Price & $3.2 \pm 2.0$ & $2.7 \pm 1.7$ & $2.9 \pm 2.1$ & $2.9 \pm 2.0$ & \\
\hline Quality & $3.0 \pm 2.9$ & $1.7 \pm 2.8$ & $1.9 \pm 2.7$ & $1.7 \pm 2.4$ & \\
\hline Total ${ }^{\dagger}$ & $20.2 \pm 12.5$ & $14.8 \pm 10.6$ & $16.1 \pm 9.3$ & $15.7 \pm 9.5$ & \\
\hline
\end{tabular}

†Maximum possible score is 54 points

One-way ANOVA Scheffe's test. Response variable=scores (avail, price, quality, total). Factor variable=poverty quartile. 
Table 12. Demographic Characteristics and Weight Status CARDIAC Participants 2009-2010

\begin{tabular}{|c|c|c|c|}
\hline \multicolumn{4}{|c|}{ County } \\
\hline & Monongalia & Marshall & Monongalia + Marshall \\
\hline Sample size (n) & 930 & 480 & 1,410 \\
\hline \multicolumn{4}{|l|}{ Gender } \\
\hline Female & 464 & 236 & 700 \\
\hline Male & 466 & 244 & 710 \\
\hline \multicolumn{4}{|l|}{ Grade } \\
\hline Kindergarten & 397 & 185 & 583 \\
\hline Second & 329 & 170 & 499 \\
\hline Fifth & 203 & 125 & 328 \\
\hline BMI percentile & $66.6 \pm 27.6$ & $65.5 \pm 28.3$ & $66.2 \pm 27.8$ \\
\hline \multicolumn{4}{|c|}{$\begin{array}{l}\text { Prevalence of BMI-for- } \\
\text { age categories }(\%)\end{array}$} \\
\hline$\geq 85^{\text {th }}$ percentile & 326 & 165 & 491 \\
\hline$\geq 95^{\text {th }}$ percentile & 155 & 89 & 244 \\
\hline$\geq 99^{\text {th }}$ percentile & 48 & 21 & 69 \\
\hline
\end{tabular}

Table 13. Parent Survey Response CARDIAC Questionnaire

\begin{tabular}{lr}
\hline \multicolumn{2}{c}{ Parent Survey Response } \\
\hline Total Students Screened & 1410 \\
Percent Screened & 42.7 \\
Parent Survey Returned & 299 \\
Survey Response Percent & 21.2 \\
Survey Complete & 235 \\
Percent Survey Complete & 16.7 \\
Percent Total Population & 7.1 \\
\hline
\end{tabular}


Table 14. Demographic Characteristics of Children with Parent Survey compared to all Students by Grade and County County (WV Department of Education Enrollment Data)

Sample (CARDIAC Parent Survey Completed)

\begin{tabular}{|c|c|c|c|c|c|c|c|c|c|c|c|c|}
\hline County & $\begin{array}{c}\begin{array}{c}\text { Number } \\
\text { of } \\
\text { Students }\end{array} \\
\end{array}$ & Grade & $\begin{array}{c}\text { Percent } \\
\text { of Total } \\
\text { by } \\
\text { Grade } \\
\end{array}$ & $\begin{array}{c}\text { Percent } \\
\text { White } \\
\text { by } \\
\text { Grade } \\
\end{array}$ & $\begin{array}{l}\text { Percent } \\
\text { Low SES } \\
\text { by Grade }\end{array}$ & $\begin{array}{c}\text { Percent } \\
\text { Male by } \\
\text { Grade }\end{array}$ & $\begin{array}{c}\text { Number } \\
\text { of } \\
\text { Students } \\
\text { Sample } \\
\end{array}$ & Grade & $\begin{array}{c}\text { Percent } \\
\text { of Total } \\
\text { by } \\
\text { Grade } \\
\end{array}$ & $\begin{array}{c}\text { Percent } \\
\text { White } \\
\text { by } \\
\text { Grade } \\
\end{array}$ & $\begin{array}{c}\text { Percent } \\
\text { Low SES } \\
\text { by } \\
\text { Grade } \\
\end{array}$ & $\begin{array}{c}\text { Percent } \\
\text { Male by } \\
\text { Grade }\end{array}$ \\
\hline Marshall & 334 & Kindergarten & 10.1 & 96.7 & 52.2 & 55.7 & 24 & Kindergarten & 10.2 & 62.5 & 79.2 & 66.7 \\
\hline Marshall & 292 & 2 & 8.8 & 95.2 & 49.6 & 49.0 & 25 & 2 & 10.6 & 96.0 & 41.3 & 40.0 \\
\hline Marshall & 372 & 5 & 11.3 & 85.8 & 51.1 & 41.1 & 6 & 5 & 2.6 & 83.3 & 50.0 & 33.3 \\
\hline Monongalia & 820 & Kindergarten & 24.8 & 86.7 & 48.3 & 51.7 & 100 & Kindergarten & 42.6 & 82.0 & 27.9 & 57.0 \\
\hline Monongalia & 734 & 2 & 22.2 & 89.4 & 48.0 & 50.1 & 59 & 2 & 25.1 & 91.5 & 20.4 & 52.5 \\
\hline Monongalia & 753 & 5 & 22.8 & 88.7 & 47.6 & 47.9 & 21 & 5 & 8.9 & 90.5 & 20.0 & 38.1 \\
\hline Total & 3305 & & 100.0 & 89.4 & 47.0 & 49.5 & 235 & & 100.0 & 86.4 & 30.2 & 52.8 \\
\hline
\end{tabular}

Within row by column between County and Sample, bold indicates differences significant at $\mathrm{p}<0.05$ (Chi Square test) 
Table 15. Odds Ratios for Risk of Obesity from Logistic Regression Analysis $n=235$

\begin{tabular}{|c|c|c|c|}
\hline \multirow{2}{*}{\multicolumn{4}{|c|}{ BMI $>95 \%$ tile }} \\
\hline & & & \\
\hline Respondent gender (parent) & 0.60 & 0.66 & $0.07,5.23$ \\
\hline Child gender & 0.95 & 0.41 & $0.41,2.23$ \\
\hline Moderate PA 6-7 days/week & $0.08 *$ & 0.09 & $0.01,0.69$ \\
\hline Servings FV/day & 0.86 & 0.12 & $0.65,1.13$ \\
\hline Fast Food per week & 0.76 & 0.22 & $0.43,1.33$ \\
\hline Parent $\mathrm{BMI} \geq 25$ & $3.77 * *$ & 1.80 & $1.48,9.62$ \\
\hline Child age $\quad-$ & 1.01 & 0.01 & $0.99,1.03$ \\
\hline Mean NEMS Score (census tract) & 1.03 & 0.04 & $0.95,1.12$ \\
\hline Family Income less than $\$ 50 K$ & $2.60 *$ & 1.21 & $1.04,6.48$ \\
\hline Median household income (tract) & 1.00 & 0.00 & $1.00,1.00$ \\
\hline Parent age & 1.04 & 0.04 & $0.97,1.11$ \\
\hline
\end{tabular}

Note. $\mathrm{CI}=$ confidence interval.

$* \mathrm{p}<0.05, * * \mathrm{p}<0.01$ 


\section{Appendix A: Letter to Store Managers \\ West VirginiaUniversity}

Davis College of Agriculture, Natural Resources, and Design

Dear Manager:

There is increasing interest in improving the community health through the promotion of healthy eating. Our group at West Virginia University is collecting data to measure the food sources that people in neighborhoods have available to them, especially restaurants and grocery/convenience stores. We are visiting restaurants in the area to look at certain things such as menus and restaurant signs, and stores to look at available foods and pricing.

We are not visiting your store or restaurant for inspection purposes, nor are they connected with your competitors. We follow strict rules to protect any information collected. We will assign an identification (ID) number to your restaurant or store, and only the research staff will see your individual store or restaurant information.

Your participation is voluntary, and you may inform us at any time if you do not wish to participate. If you have questions or concerns, please contact me at 304-293-1938. Thank you for allowing us to spend a few minutes in your restaurant or store to record this information.

Sincerely,

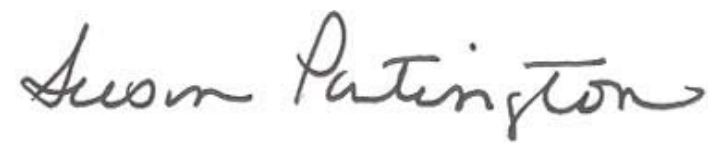

Susan Partington, PhD, RD

Associate Professor

Davis College of Agriculture, Natural Resources, and Design

Animal and Nutritional Sciences

Susan.Partington@mail.wvu.edu

Human Nutrition and Foods

Division of Animal \& Nutritional Sciences

Phone: 304-293-2631

Fax: 304-293-2232
P.O. Box 6108

Morgantown, WV 26506 


\section{Nutrition Environment Measures Survey (NEMS)}

Measure \#1: MILK

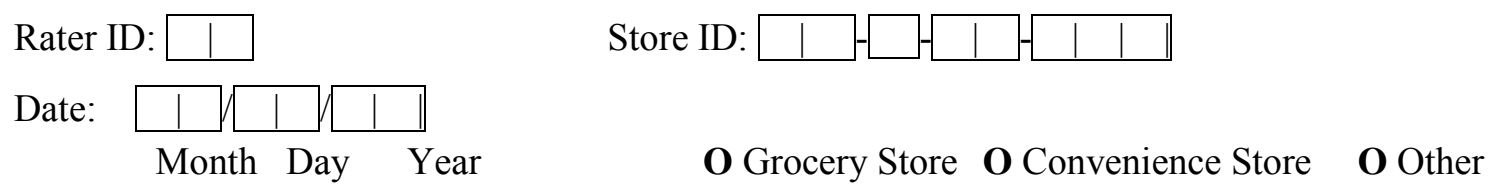

\section{Marking Instructions}

Please use a pencil or blue or black ink

A. Reference Brand

1. Store brand (preferred)

$\mathbf{O}$ yes $\mathbf{O}$ no

2. Alternate Brand Name

Comments:

B.

\section{Availability}

$\mathbf{O}$ Yes $\mathbf{O}$ No

1. a. Is low-fat (skim or 1\%) available?

b. If not, is $2 \%$ available?

O Yes O No O NA

2. Shelf Space: (measure only if low fat milk is available)
Type
a. Skim
b. $1 \%$
c. Whole

Pint
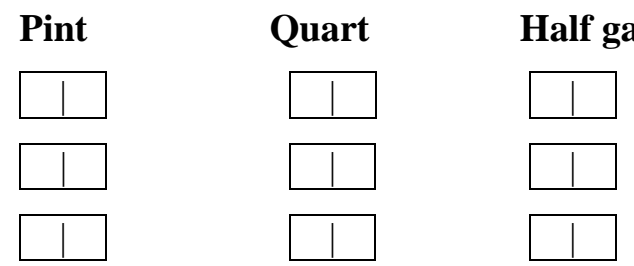

Gallon

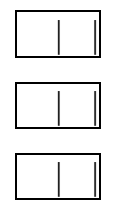

C. Pricing: All items should be same brand

Comments:

1. Whole milk, quart

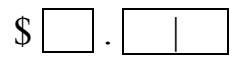

2. Whole milk, half-gal.

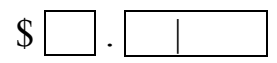

3. Skim or $1 \%$ milk, quart

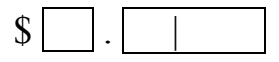

(Lowest available)

4. Skim or $1 \%$ milk half-gal.

(Lowest available)

Alternate Items:
5. $2 \%$, quart
$\$ \square . \square \quad$ O N/A
6. $2 \%$, half gal.
$\$ \square \cdot \square \quad$ O N/A

Comments:

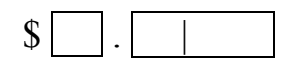


Nutrition Environment Measures Survey (NEMS)

Measure \#2: FRUIT

Rater ID:

Date:

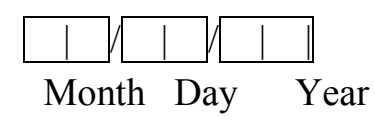

Availability and Price

Produce Item

1. Bananas

2. Apples

O Red delicious $\mathbf{O} \mathbf{O}$

O

3. Oranges

O Navel

O O

O

4. Grapes

O Red Seedless

O

5. Cantaloupe

6. Peaches

7. Strawberries

8. Honeydew Melon

9. Watermelon

O Seedless

O O

$\$ \square$
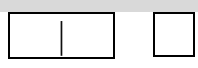

O O O O O

10. Pears

O Anjou

O O

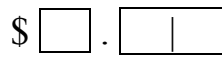

O Convenience Store O Other

$\begin{array}{lrlrrr}\begin{array}{l}\text { Available } \\ \text { Yes No }\end{array} & \text { Price } & \begin{array}{r}\text { Unit } \\ \text { pc }\end{array} & \begin{array}{r}\text { Quality } \\ \text { A }\end{array} & \text { Comments } \\ \text { O O } & \$ \square \cdot \square & \text { OA O } & \text { O O } & \end{array}$

\section{O}

11. Total Types: (count \# of yes responses) 
Nutrition Environment Measures Survey (NEMS)

Measure \#3: VEGETABLES

Rater ID:

Store ID:

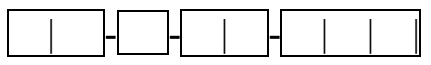

Date:

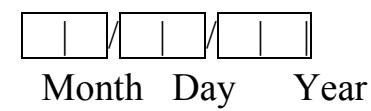

$\mathbf{O}$ Grocery Store $\mathbf{O}$ Convenience Store $\mathbf{O}$ Other

Availability and Price

\begin{tabular}{|c|c|c|c|c|c|c|c|}
\hline \multirow{2}{*}{\multicolumn{2}{|c|}{ Produce Item }} & \multirow{2}{*}{$\begin{array}{c}\text { Available } \\
\text { Yes No }\end{array}$} & \multirow[t]{2}{*}{ Price } & \multicolumn{2}{|r|}{ Unit } & Quality & \multirow[t]{2}{*}{ Comments } \\
\hline & & & & \# & oc $\mathrm{lb}$ & A $\mathbf{U A}$ & \\
\hline \multirow[t]{2}{*}{ 1. Carrots } & O $1 \mathrm{lb}$ bag & O O & $\$ \square$ & & O O & O O & \\
\hline & $\mathbf{O}$ & & & & & & \\
\hline \multirow[t]{2}{*}{ 2. Tomatoes } & O Loose & O 0 & $\$[$ & & O O & O 0 & \\
\hline & O & & & & & & \\
\hline \multirow[t]{2}{*}{ 3. Sweet Peppers } & O Green bell & O 0 & $\$[$ & & O O & O O & \\
\hline & $\mathbf{O}$ & & & & & & \\
\hline \multirow[t]{2}{*}{ 4. Broccoli } & O Bunch & O 0 & $\$[$ & & O O & O O & \\
\hline & $\mathbf{0}$ & & & & & & \\
\hline \multirow[t]{2}{*}{ 5. Lettuce } & $\mathbf{O}$ Green leaf & O 0 & $\$[$ & & O O & O O & \\
\hline & $\mathbf{O}$ & & & & & & \\
\hline \multicolumn{2}{|l|}{ 6. Corn } & O 0 & $\$[$ & & O O & O O & \\
\hline \multicolumn{2}{|l|}{ 7. Celery } & O 0 & $\$$ & & O O & O O & \\
\hline \multirow[t]{2}{*}{ 8. Cucumbers } & O Regular & O 0 & $\$$ & & O O & O O & \\
\hline & $\mathbf{O}$ & & & & & & \\
\hline \multirow[t]{2}{*}{ 9. Cabbage } & O Head & O O & $\$$ & & OO & O O & \\
\hline & $\mathbf{O}$ & & & & & & \\
\hline \multicolumn{2}{|l|}{ 10. Cauliflower } & O 0 & $\$[$ & 4 & O O & O 0 & \\
\hline
\end{tabular}

11. Total Types: (count \# of yes responses) 


\section{Nutrition Environment Measures Survey (NEMS)}

Measure \#4: GROUND BEEF

Rater ID:

Date:

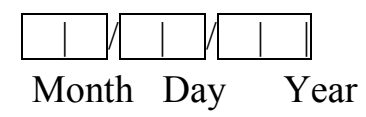

Store ID:

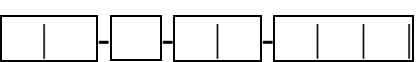

\section{Availability and Price}

\section{Item}

\section{Healthier Option:}

1. Lean ground beef, $\mathbf{9 0 \%}$ lean, 10\% fat (Ground Sirloin)
Available

Yes No N/A

O O
Price/lb.

\section{Comments}

Price/lb.

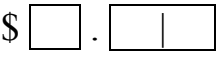
Yes No N/A
O O O
Alternate Items:
2. Lean ground beef $(<10 \%$ fat $)$

1 $\%$ fat

3. Ground Turkey ( $\leq 10 \%$ fat $)$

O O O

$\$$

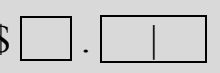

\begin{tabular}{l}
\hline \\
\hline
\end{tabular} fat

4. \# of varieties of lean ground beef $(\leq 10 \%$ fat $)$

O 0

O 1

$\mathbf{O}$

O 3

O 4

O 5

O 6+

\section{Regular option:}

5. Standard ground beef, $80 \%$ lean, $\quad$ O O

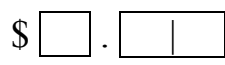

$20 \%$ fat

\section{Alternate Item:}

6. Standard alternate ground beef, if above is not available

\section{Yes No N/A}

O O O

$\$$

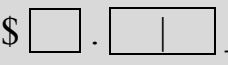

\section{$\%$ fat}




\section{Nutrition Environment Measures Survey (NEMS) \\ Measure \#5: HOT DOG}

Rater ID:

Date:

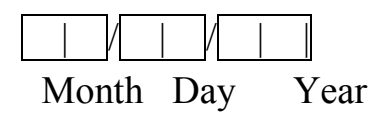

Store ID:

\section{$\mathbf{O}$ Grocery Store $\mathbf{O}$ Convenience Store $\mathbf{O}$ Other}

Availability and Price

\section{Item}

\section{Healthier Option:}

1. Oscar Mayer $98 \%$ Fat-free Wieners (turkey/beef) $0 \mathrm{~g}$ fat

Alternate Items: $(\leq 9$ g Fat $)$

2. Fat-free other brand $0 \mathrm{~g}$ fat

\begin{tabular}{|l|l|l|l|l|l|}
\hline $\mid$ & $\mid$ & $\mid$ & $\mid$ & $\mid$ & $\mid$
\end{tabular}

Brand name

3. Light Wieners (turkey/pork)

4. Light beef Franks, (about $1 / 3$ less calories $50 \%$ less fat)

5. Turkey Wieners (about $1 / 3$ less fat)

6. Other

\section{Available Price/pkg.}

Yes No N/A

Yes $\mathrm{No}$ N/A

O O

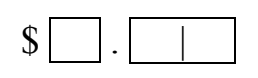

\section{Comments}

Yes No N/A

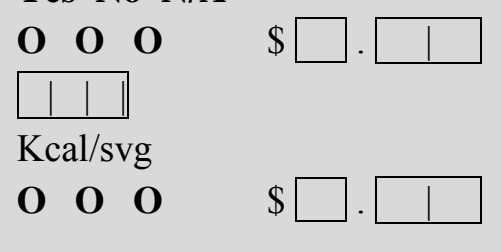

O O O

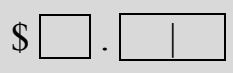

O O O

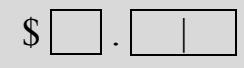

O O O

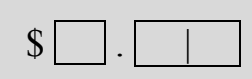

$\square$ oz pkg $\square$ Hot dogs/pkg $\square \mathrm{g}$ fat $\quad \mathrm{kcal} / \mathrm{svg}$

\section{Regular option:}

7. Oscar Mayer Wieners

O 0

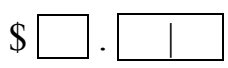

(turkey/pork/chicken)-regular 12g fat

Alternate Items: ( $\geq 10 \mathrm{~g}$ fat)

8. Beef Franks (regular) $13 \mathrm{~g}$ fat

O O O

$\$ \square \cdot \square$

9. Other

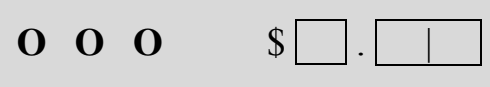

I oz pkg | Hot dogs/pkg $\square$ g fat $\square \mathrm{kcal} / \mathrm{svg}$ 


\section{Nutrition Environment Measures Survey (NEMS) \\ Measure \#6: FROZEN DINNERS}

Rater ID:

Store ID:

Date:

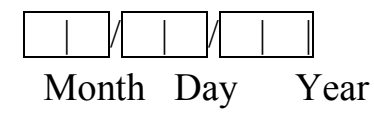

\section{$\mathbf{O}$ Grocery Store $\mathbf{O}$ Convenience Store $\mathbf{O}$ Other}

\section{A. Reference Brand}

1, Stouffer's brand (preferred)

O Yes $\mathbf{O}$ No

2. Alternate brand (with reduced-fat dinners

available) Brand Name:

Comments:

\section{B. Availability}

1. Are reduced-fat frozen dinners

available? ( $\leq 9 \mathrm{~g}$ fat $/ 8-11 \mathrm{oz}$.)

Shelf Space: (measure only if reduced-fat frozen dinners are available)

2. Reduced-fat dinners/regular dinners: Proportion

O $<=10 \% \quad$ O $11-33 \% \quad$ O $34-50 \% \quad$ O $51 \%+$

C. Pricing (All items must be same brand)

\section{Reduced-Fat Dinner Price/Pkg}

1. Lean Cuisine Lasagna

$$
\begin{array}{|l|l|l|l}
\hline & \text { oz } & \text { K cal. }
\end{array}
$$

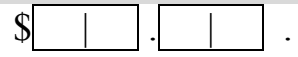

\section{Lean Cuisine Roasted}

\section{Turkey Breast}

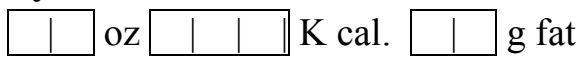

\section{Lean Cuisine Meatloaf}

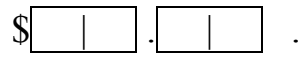

\begin{tabular}{|l|l|l|}
\hline$\square$ & oz \\
\hline & K cal. $\square \mathrm{g}$
\end{tabular}

\section{Reduced-Fat Alternate ( $\leq 9 \mathrm{~g}$ fat)}

\section{Price/Pkg}

4. Other

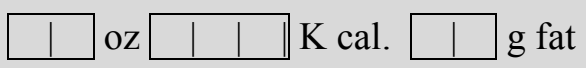

5. Other

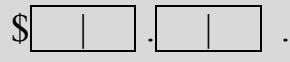

\begin{tabular}{|l|l|l}
$\square$ & oz \\
\hline & K cal. & $\mathrm{g}$ fat
\end{tabular}

6. Other

$\square$ oz 1 I K cal. $\square$ g fat

Regular Dinner Price/Pkg Comments

Stouffer's Lasagna $\$$

\begin{tabular}{|l|l|l|l|l|l}
\hline & oz & K & cal. & g fat
\end{tabular}

Stouffer's Roasted

Turkey Breast

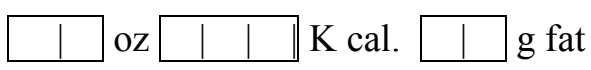

Stouffer's Meatloaf \$

\begin{tabular}{|l|l|l|l|l|}
\hline & oz & K cal. & | & g fat
\end{tabular}

Regular Alternate $(\geq 10 \mathrm{~g}$ fat) Price/Pkg Comments

Other

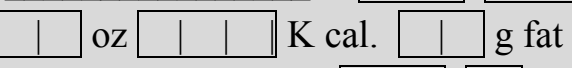

Other
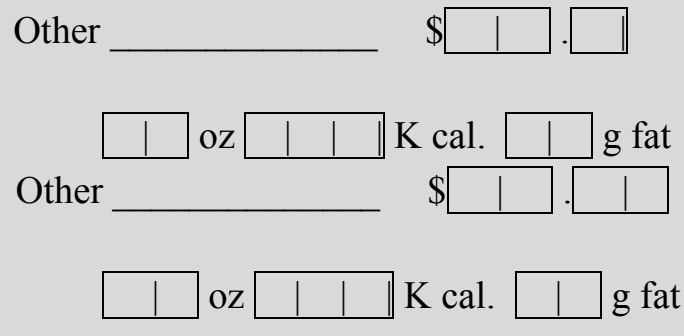


\section{Nutrition Environment Measures Survey (NEMS)}

Measure Complete

\section{Measure \#7: BAKED GOODS}
Rater ID:
Store ID: $\square|-\square-\square-\square-\square|$
Date:

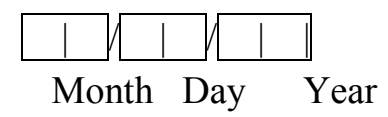
$\mathbf{O}$ Grocery Store $\mathbf{O}$ Convenience Store $\quad \mathbf{O}$ Other

Availability \& Price

Low-fat baked goods $\leq 3 \mathrm{~g}$ fat $/$ serving

$\begin{array}{lllllll}\text { Item } & \begin{array}{l}\text { Available } \\ \text { Yes No }\end{array} & \begin{array}{l}\text { Amt. per } \\ \text { package }\end{array} & \begin{array}{l}\text { g fat/ } \\ \text { per item }\end{array} & \begin{array}{c}\text { kcal/ } \\ \text { per item }\end{array} & \text { Price } & \text { Comments } \\ & \text { Yes } & & & \end{array}$

\section{Healthier option:}

1. Bagel

Single

O O
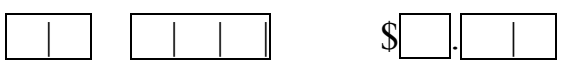

Yes No N/A

Package
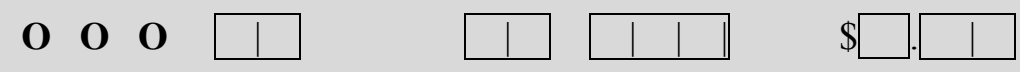

Alternate Items: $\quad$ Yes No N/A

2. English muffin

O O O
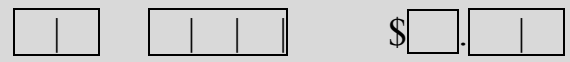

3. a. Low-fat muffin

O O O
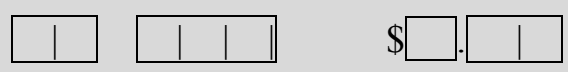

\section{$\perp \perp|||||| \mid \perp$}

b. \# varieties of low fat muffins

O $0 \quad$ O 1 O $2 \quad$ O $3+$

Regular option ( $>3 \mathrm{~g}$ fat/serving or $400 \mathrm{Kcal} /$ serving):
4. Regular muffin
O 0
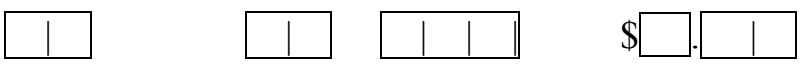

Alternate Items

Yes No N/A

5. Regular Danish

O O O

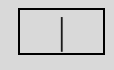

6. Other

O 00
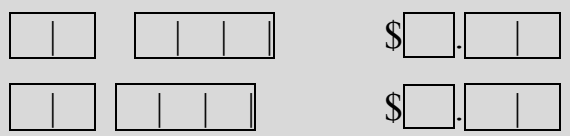


\section{Nutrition Environment Measures Survey (NEMS)}

\section{Measure \#8-CS-BEVERAGE}

Rater ID

Store ID:

$\mathbf{O}$ Grocery Store $\quad \mathbf{O}$ Convenience Store $\quad \mathbf{O}$ Other

Date:

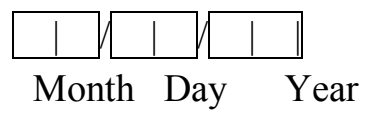

\section{Availability \& Price}

Healthier option:

1. Diet Coke

2. Alternate brand of diet soda

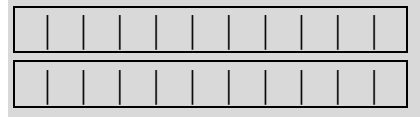

Available

Yes No

12 oz. O O

20 oz. O O

Yes No N/A

12 oz. O O O

$20 \mathrm{oz}$. O O O
Price

Comments

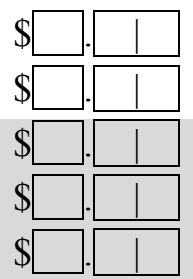

Regular option:

3. Coke

4. Alternate brand of sugared soda

\section{Yes No}

12 oz. O O

$20 \mathrm{oz}$. O O

Yes No N/A

12 oz. O O O

$20 \mathrm{oz}$. O O O
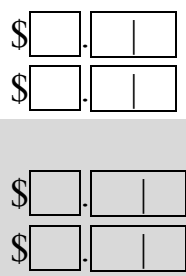

Healthier option:

$5.100 \%$ juice, $15.2 \mathrm{oz}$.

O Minute Maid $\mathbf{O}$ Tropicana $\mathbf{O}$ Other

Alternate Items:

6. $100 \%$ juice, $14 \mathrm{oz}$.

O Minute Maid $\mathbf{O}$ Tropicana $\mathbf{O}$ Other

7. $100 \%$ juice, oz.

O Minute Maid $\mathbf{O}$ Tropicana $\mathbf{O}$ Other

\section{Regular option:}

8. Juice Drink, $15.2 \mathrm{oz}$

O Minute Maid $\mathbf{O}$ Tropicana $\mathbf{O}$ Other

Alternate Items:

9. Juice Drink, 14 oz.

O Minute Maid $\mathbf{O}$ Tropicana $\mathbf{O}$ Other 10. Juice Drink, oz.

O Minute Maid $\mathbf{O}$ Tropicana $\mathbf{O}$ Other
Yes No

O O

Yes No N/A

O O O

O O O
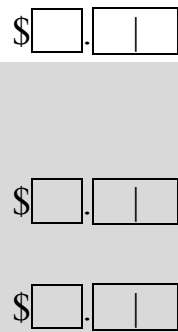

Yes No

O O

Yes No N/A

O O O

O O O
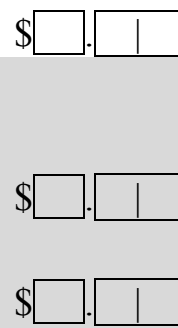


\section{Nutrition Environment Measures Survey (NEMS)}

Rater ID:

Date:

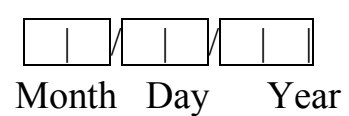

Store ID:

O Grocery Store

O Convenience Store
O Other

\section{Availability \& Price}

Item

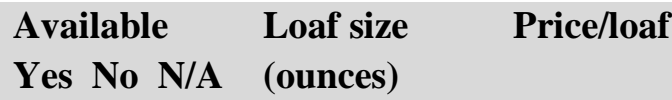

Comments

Healthier Option: Whole grain bread (100\% whole wheat bread and whole grain bread)
1. Nature's Own 100\% Whole
O 0
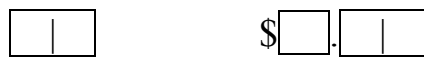

Wheat Bread

\section{Alternate Items:}

2. Sara Lee Classic 100\% Whole

O O O
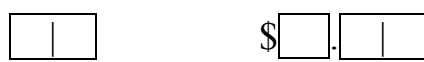

Wheat Bread

3. Other:

Yes No N/A

O O O
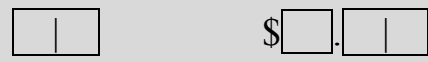

4. \# of varieties of $100 \%$ whole wheat bread and whole grain (all brands)
$\begin{array}{llll}\mathbf{O} 0 & \text { O } 1 & \text { O } 2\end{array}$
$\begin{array}{llll}\text { O } 3 & \text { O } 4 & \text { O } 5 & \text { O } 6+\end{array}$

Regular Option: White bread (bread made with refined flour)

5. Nature's Own Butter Bread

O O

1

\section{Alternate Items:}

Yes No N/A

6. Sara Lee Classic White Bread

O O O
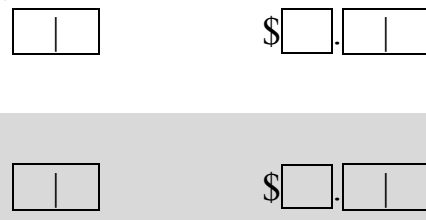

7. Other:

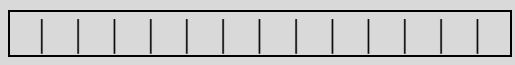

O $\mathbf{O} \mathbf{O}$

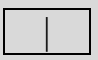




\section{Nutrition Environment Measures Survey (NEMS) Measure \#10: BAKED CHIPS}

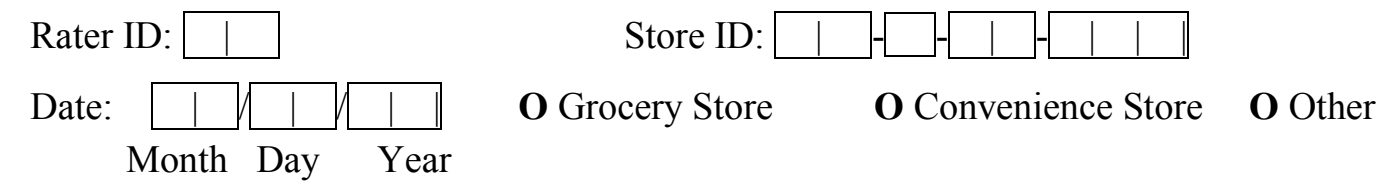

\section{Availability \& Price}

Low-fat chips $\leq 3 \mathrm{~g}$ fat per $1 \mathrm{oz}$. serving

\begin{tabular}{lrrrr} 
Item & $\begin{array}{c}\text { Size } \\
\text { (ounces) }\end{array}$ & Available & Price & Comments \\
Healthier Option : & \multicolumn{5}{c}{ Yes No } \\
ked Lays Potato Chips & $\square$ oz. & O & O & $\$ \square . \square$
\end{tabular}

\section{Alternate Item:}

2

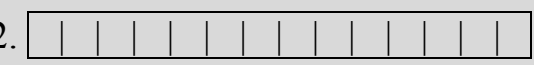

Yes No N/A

O O O

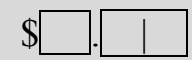

oz.

3. \# of varieties of low-fat chips (any brand)
$\mathbf{O} 0$
O $1 \quad$ O 2
O 3
O 4
O 5
O $6+$

Regular Option (select most comparable size to healthier option available):

\begin{tabular}{|c|c|c|c|}
\hline & Size & Yes No & Price \\
\hline 4. Lays Potato Chips Classic & oz. & $\mathbf{O} \mathbf{O}$ & $\$$ \\
\hline
\end{tabular}

Alternate Item:

1. Baked Lays Potato Chips

O

O O

Yes No N/A

O 00

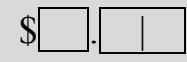

oz. 


\section{Nutrition Environment Measures Survey (NEMS)}

\section{Measure \#11: CEREAL}

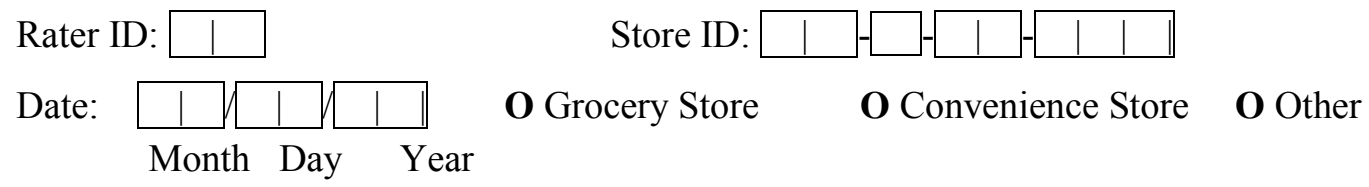

Availability \& Price

Healthier cereals $<7$ g sugar per serving

$\begin{array}{llll}\text { Available } & \text { Size } & \text { Price } & \text { Comments }\end{array}$

Item

Yes No N/A (ounces)

\section{Healthier Option:}

1. Cheerios (Plain) $\quad$ O O

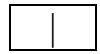

$\$ \square . \square$

Alternate Item:

Yes No N/A

2. Other

O 00

$\$ \square \cdot \square$

3. \# of varieties of healthier cereals

$\begin{array}{lllll}\mathbf{O} 0 & \mathbf{O} 1 & \mathbf{O} 2 & \mathbf{O} 3+\end{array}$

Regular Options ( $\geq 7 \mathrm{~g}$ of sugar per serving):

4. Cheerios (Flavored) _ O O

Alternate Item: Yes No N/A

5. Other

O O O

1
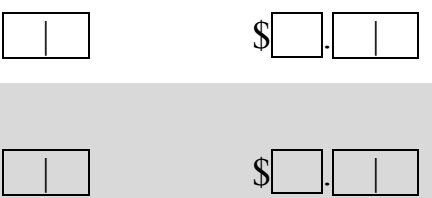


\section{Appendix C: IRB Certificate of Completion}

\section{CITI Collaborative Institutional Training Initiative}

\section{Human Research Curriculum Completion Report \\ Printed on 10/13/2010}

Learner: Anna Chetrick (username: achetric)

Institution: West Virginia University

Contact Information Department: Animal \& Nutritional Sciences

Email: achetric@mix.wvu.edu

Biomedical Research Investigators:

Stage 1. Basic Course Passed on 04/09/10 (Ref \# 4300655)

\begin{tabular}{|c|c|c|}
\hline Required Modules & \begin{tabular}{|c|} 
Date \\
Completed
\end{tabular} & \\
\hline Belmont Report and CITI Course Introduction & $04 / 08 / 10$ & $2 / 3(67 \%)$ \\
\hline History and Ethical Principles & $04 / 08 / 10$ & $7 / 7(100 \%)$ \\
\hline $\begin{array}{l}\text { Basic Institutional Review Board (IRB) Regulations and } \\
\text { Review Process- }\end{array}$ & $04 / 08 / 10$ & $4 / 5(80 \%)$ \\
\hline Informed Consent & $04 / 08 / 10$ & $4 / 4(100 \%)$ \\
\hline Records-Based Research & $04 / 08 / 10$ & $1 / 2(50 \%)$ \\
\hline $\begin{array}{l}\text { Research With Protected Populations - Vulnerable Subjects: } \\
\text { An Overview }\end{array}$ & $04 / 08 / 10$ & $2 / 4(50 \%)$ \\
\hline Vulnerable Subjects - Research Involving Minors & $04 / 09 / 10$ & $3 / 3(100 \%)$ \\
\hline $\begin{array}{l}\text { Group Harms: Research With Culturally or Medically } \\
\text { Vulnerable Groups }\end{array}$ & $04 / 09 / 10$ & $3 / 3(100 \%)$ \\
\hline FDA-Regulated Research & $04 / 09 / 10$ & $4 / 5(80 \%)$ \\
\hline Research and HIPAA Privacy Protections & $04 / 09 / 10$ & $2 / 2(100 \%)$ \\
\hline Conflicts of Interest in Research Involving Human Subjects & $04 / 09 / 10$ & $2 / 2(100 \%)$ \\
\hline West Virginia University & $04 / 09 / 10$ & no quiz \\
\hline
\end{tabular}

For this Completion Report to be valid, the learner listed above must be affiliated with a CITI participating institution. Falsified information and unauthorized use of the CITI course site is unethical, and may be considered scientific misconduct by your institution.

Paul Braunschweiger Ph.D.

Professor, University of Miami

Director Office of Research Education

CITI Course Coordinator 
Appendix D: NEMS Certificate of Training Completion

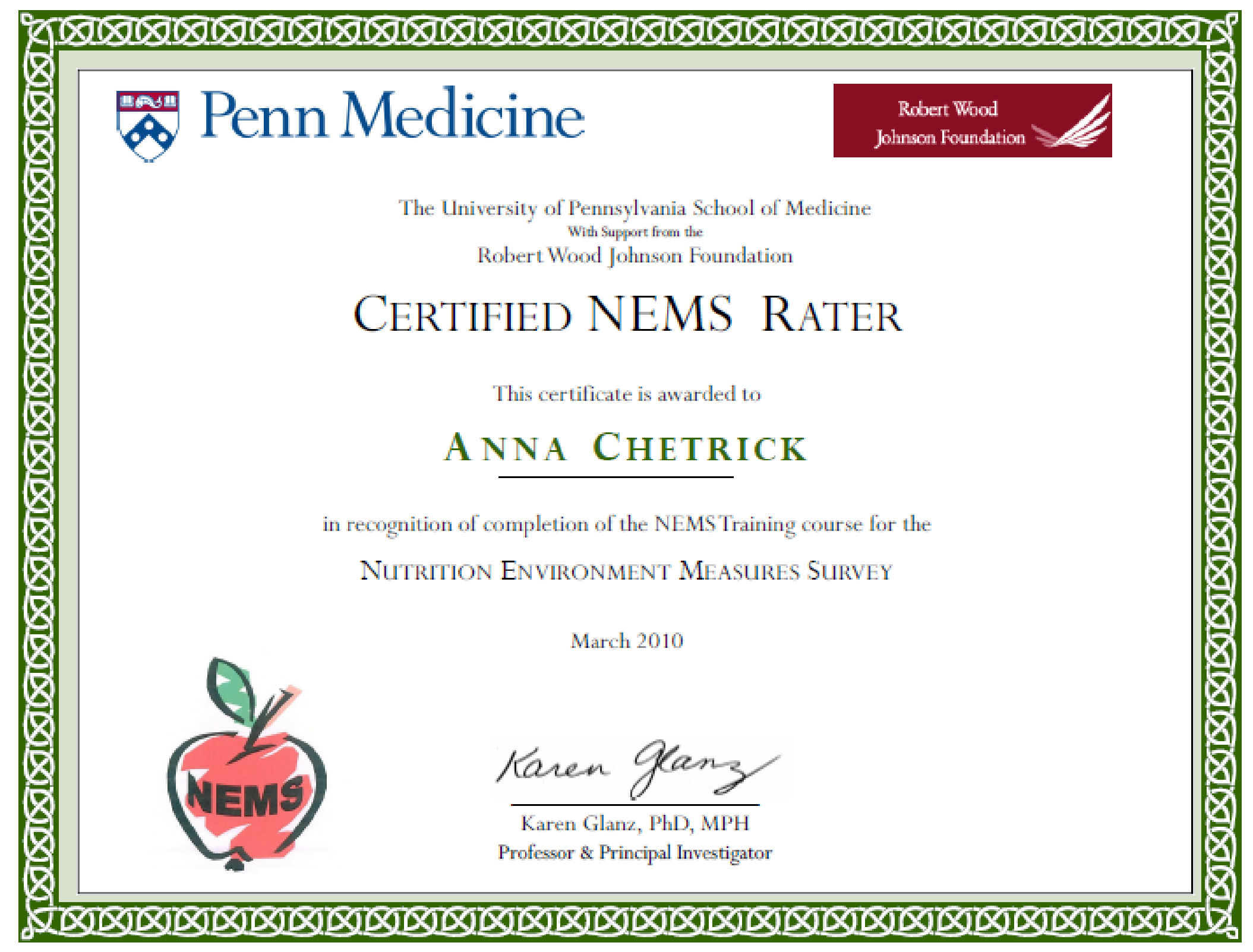




\section{Appendix E: Parent Survey}

पT

10053

Parent Pre-Assessment

Environmental Determinants of Physical Activity in Children \& Teens

-Please fill in entire answer circle-

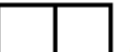

/

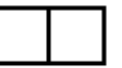

/

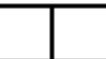

1. Who is the main person completing this form:

O Mother

O Father

O Other

2. How would you describe the area where you live?

O Rural O Town / Suburb O City / Urban

3. Do you plan to speak with your child's pediatrician about your child's CARDIAC screening?

O Already discussed my child's CARDIAC screening with my child's pediatrician

O Plan to discuss with my child's pediatrician and I have scheduled an appointment to do so

O Plan to discuss with my child's pediatrician but I have not scheduled an appointment to do so

O Do not plan to discuss my child's CARDIAC screening with my child's pediatrician

4. Does your child have any medical conditions or disabilities that limit his or her physical activity?

O No O Yes, please list conditions:

5a. How do you describe your child's weight?
$O$ Very underweight
O Slightly underweight
O About the right weight
O Slightly overweight
O Very overweight

5b. Please indicate how concerned you are about your child's weight?

$O$ Very concerned OA little concerned O Not concerned

6. Please rate your child's physical activity level using a scale of 0 to 7 .

O 0

No activity

O 1

$\mathrm{O} 2$

O 3

$\mathrm{O} 4$

O 5

O 6

Very active

7. Compared to other children of the same age and sex, how would you describe your child's physical activity level?

Much less than others

O Somewhat less than others

About the same

Somewhat more than others

O Much more than others

8a. On how many of the past 7 days did your child exercise or participate in physical activities for at least 20 minutes that made him or her sweat and breathe hard, such as basketball, soccer, running, swimming, laps, fast bicycling, fast dancing, or similar aerobic activites?
O 0 days
O 1 day
O 2 days
O 3 days
O 4 days
O 5 days
O 6 days
O 7 days

$8 \mathrm{~b}$. On how many of the past 7 days did your child participate in physical activity for at least $\mathbf{3 0}$ minutes that did NOT make him or her sweat or breathe hard, such as fast walking, slow bicycling, skating, pushing a lawn mower, or mopping floors?
O 0 days
O 1 day
O 2 days
O 3 days
O 4 days
O 5 days
O 6 days
O 7 days 


\section{IN THIS SECTION, WE WILL ASK ABOUT YOUR ACTIVITY PREFERENCES AND YOUR CHILD'S ACTIVITY PREFERENCES.}

9. For each pair, please indicate the one activity $\underline{Y O U}$ prefer to do:

\begin{tabular}{|c|c|}
\hline 0 Swimming & OR $O$ Reading \\
\hline O Swimming & OR O Arts \& crafts, scraphooking \\
\hline O Swimming & oR O Screen time (computer, TV, non-active video games) \\
\hline O Riding a bike / Using exercise equipment & OR $O$ Reading \\
\hline O Riding a bike / Using exercise equipment & OR $O$ Arts \& crafts, scrapbooking \\
\hline O Riding a bike / Using exercise equipment & OR O Screen time (computer, TV, non-active video games) \\
\hline O Walking/Jagging & OR $O$ Reading \\
\hline O Walking / Jogging & OR $\bigcirc$ Arts \& crafts, scrapbooking \\
\hline O Walking / Jogging & OR $\bigcirc$ Screen time (computer, TV, non-active video games) \\
\hline
\end{tabular}

10. For each pair, please indicate the one activity YOUR CHILD prefers to do:

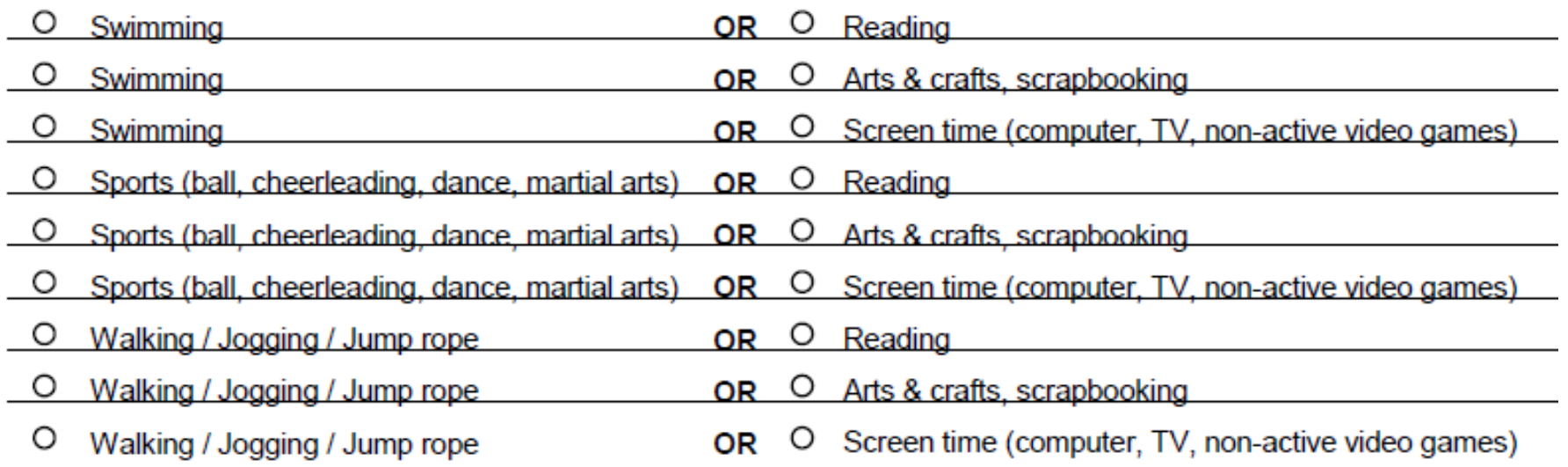

11. How much does your child enjoy physical activity?
O Strongly dislikes
O Dislikes
O Somewhat dislikes
O Somewhat likes
O Likes
O Strongly likes

12. On average, how many hours per day does your child have screen time (watch TV, use computer, play video games):

Weekdays (Monday-Friday) Weekend (Saturday \& Sunday)

\begin{tabular}{lll}
\hline & Less than 1 & 0 \\
\hline 0 & Between 1 and 2 & 0 \\
\hline$O$ & Between 2 and 3 & 0 \\
\hline$O$ & Between 3 and 4 & 0 \\
\hline$O$ & Between 4 and 5 & 0 \\
\hline$O$ & More than 5 & 0
\end{tabular}


13. Directions: Make a vertical line at the point where you make the decisions, in your home.

EXAMPLE: Who makes the decisions about what your child wears.

\begin{tabular}{l|c}
$\begin{array}{l}\text { Decision based completely } \\
\text { by parents }\end{array}$ & $\begin{array}{c}\text { Decision based completely } \\
\text { by child }\end{array}$
\end{tabular}

1. Decisions about what your child eats while at home.

For office use

Completely by parent

Completely by child

Decisions about what your child eats while away from home.

Completely by parent

Completely by child
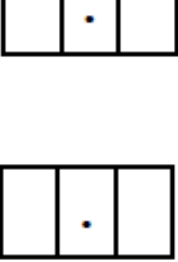

3. Decisions about the type of physcial activities your child engages in while at home.

Completely by parent

Completely by child

4. Decisions about the type of physical activities your child engages in while away from home.

Completely by parent

Completely by child

5. Decisions about how much activity your child has while at home.

Completely by parent

Completely by child

6. Decisions about how much activity your child has while away from home.

Completely by parent

Completely by child

7. Decisions about what foods are bought for meals at home.

Completely by parent

Completely by child

8. Decisions to eat out.

Completely by parent

Completely by child

9. Decisions about food purchased at the grocery store.

Completely by parent

Completely by child
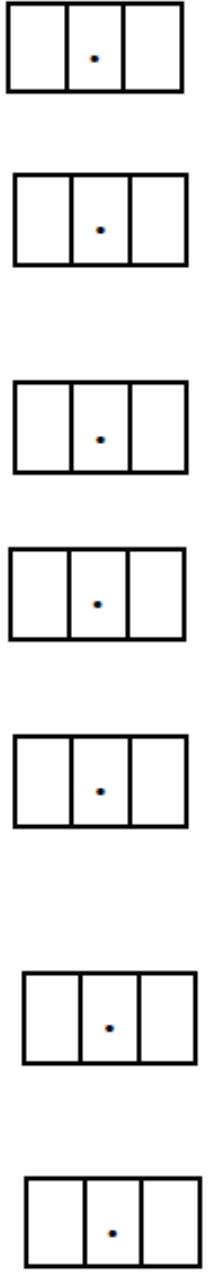


\section{Please indicate HOW OFTEN:}

Never Rarely Sometimes Often Always

A. You express affection by hugging, kissing, \& holding your child

B. You hug or hold your child for no particular reason

C. You tell vour child how havbv he/she makes vou

$\begin{array}{lllll}0 & 0 & 0 & 0 & 0\end{array}$

D. You have warm, close times together with your child

E. You enjoy doing things with your child

F. You feel close to your child both when he/she is happy \& when he/she is upset

\begin{tabular}{|c|c|c|c|c|c|}
\hline $\begin{array}{l}\text { G. You make sure your child follows an instruction or make a } \\
\text { request to do something }\end{array}$ & $\mathrm{O}$ & $\mathrm{O}$ & $\mathrm{O}$ & $\mathrm{O}$ & $\mathrm{O}$ \\
\hline H. You are angry when you punish your child & 0 & $\mathrm{O}$ & $\mathrm{O}$ & $\mathrm{O}$ & $\mathrm{O}$ \\
\hline I. You feel you are having problems managing your child in general & $\mathrm{O}$ & $\mathrm{O}$ & $\mathrm{O}$ & $\mathrm{O}$ & $\mathrm{O}$ \\
\hline $\begin{array}{l}\text { J. You punish your child for continuing to do something after being } \\
\text { told to stop }\end{array}$ & $\mathrm{O}$ & $\mathrm{O}$ & $\mathrm{O}$ & $\mathrm{O}$ & $\mathrm{O}$ \\
\hline $\begin{array}{l}\text { K. Your child gets away with things that you feel should have been } \\
\text { punished }\end{array}$ & $\mathrm{O}$ & $\mathrm{O}$ & $\mathrm{O}$ & $\mathrm{O}$ & $\mathrm{O}$ \\
\hline $\begin{array}{l}\text { L. Your child is able to get out of punishment when he/she really } \\
\text { sets his/her mind to it }\end{array}$ & $\mathrm{O}$ & $\mathrm{O}$ & $\mathrm{O}$ & $\mathrm{O}$ & $\mathrm{O}$ \\
\hline M. Your child ignores the punishment when you discipline him/her & $\mathrm{O}$ & $\mathrm{O}$ & $\mathrm{O}$ & $\mathrm{O}$ & $\mathrm{O}$ \\
\hline $\begin{array}{l}\text { N. You express praise when talking with your child about his/her } \\
\text { behavior }\end{array}$ & $\mathrm{O}$ & 0 & $\mathrm{O}$ & $\mathrm{O}$ & $\mathrm{O}$ \\
\hline $\begin{array}{l}\text { O. You express disapproval when talking with your child about } \\
\text { his/her behavior }\end{array}$ & O & O & O & $\mathrm{O}$ & $\mathrm{O}$ \\
\hline
\end{tabular}
his/her behavior

\section{Please indicate HOW OFTEN you do the following in front of your child:}

\begin{tabular}{|c|c|c|c|c|c|}
\hline & Never & Rarely & Sometimes & Often & Always \\
\hline A. Being physically active & O & O & O & $\mathrm{O}$ & $\mathrm{O}$ \\
\hline B. Doing house/yard work & $\mathrm{O}$ & $\mathrm{O}$ & $\mathrm{O}$ & $\mathrm{O}$ & $\mathrm{O}$ \\
\hline C. Using physical activity as relaxation & $\mathrm{O}$ & $\mathrm{O}$ & $\mathrm{O}$ & $\mathrm{O}$ & $\mathrm{O}$ \\
\hline D. Being too tired to be physically active & $\mathrm{O}$ & $\mathrm{O}$ & $\mathrm{O}$ & $\mathrm{O}$ & $\mathrm{O}$ \\
\hline E. Eating healthy snacks & $\mathrm{O}$ & $\mathrm{O}$ & $\mathrm{O}$ & $\mathrm{O}$ & $\mathrm{O}$ \\
\hline F. Eating meals at the table & $\mathrm{O}$ & $\mathrm{O}$ & $\mathrm{O}$ & $\mathrm{O}$ & $\mathrm{O}$ \\
\hline G. Taking second helpings & $\mathrm{O}$ & $\mathrm{O}$ & $\mathrm{O}$ & $\mathrm{O}$ & $\mathrm{O}$ \\
\hline H. Eating unhealthy snacks & $\mathrm{O}$ & $\mathrm{O}$ & $\mathrm{O}$ & $\mathrm{O}$ & $\mathrm{O}$ \\
\hline I. Talking positively about sports or physical activity & $\mathrm{O}$ & $\mathrm{O}$ & $\mathrm{O}$ & $\mathrm{O}$ & $\mathrm{O}$ \\
\hline J. Eating while watching TV/reading & O & $\mathrm{O}$ & $\mathrm{O}$ & $\mathrm{O}$ & $\mathrm{O}$ \\
\hline K. Eating when you are in a bad mood/angry & $\mathrm{O}$ & $\mathrm{O}$ & $\mathrm{O}$ & $\mathrm{O}$ & $\mathrm{O}$ \\
\hline L. Eating late at night & $\mathrm{O}$ & $\mathrm{O}$ & $\mathrm{O}$ & $\mathrm{O}$ & $\mathrm{O}$ \\
\hline M. Drinking sugar-sweetened drinks (soda, kool-aid, & $\mathrm{O}$ & $\mathrm{O}$ & $\mathrm{O}$ & $\mathrm{O}$ & $\mathrm{O}$ \\
\hline
\end{tabular}


16. As a parent, I feel...

Strongly Disagree Neutral Agree Strongly

A. Successful about my efforts to help my child stay physically active $0 \quad 0 \quad 0 \quad 0$

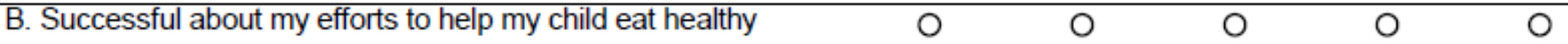

$\begin{array}{llllll}\text { C. I make a significant difference in my child's health } & 0 & 0 & 0 & 0 & 0\end{array}$

$\begin{array}{llllll}\text { D. I do not know how to help my child stay physically active } & 0 & 0 & 0 & 0 & 0\end{array}$

$\begin{array}{llllll}\text { E. I do not know how to help my child eat healthy } & 0 & 0 & 0 & 0 & 0\end{array}$

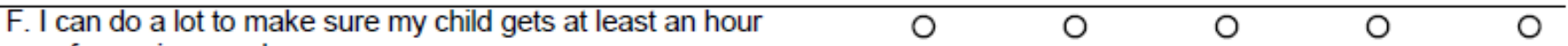
of exercise per day

$\begin{array}{lllll}\text { G. I can do a lot to make sure my child eats fruits and } & 0 & 0 & 0 & 0\end{array}$ vegetables every day

\begin{tabular}{llllll} 
H. It costs too much money to help my child be physically active & 0 & 0 & $O$ & $O$ & $O$ \\
\hline
\end{tabular}

I. The financial cost keeps me from enrolling my child in sports teams or organized physical activity (gymnastics, martial arts)

$\begin{array}{lllll}\text { J. I have a hard time transporting (driving) my child to } & 0 & 0 & 0 & 0\end{array}$ events or places to be physically active

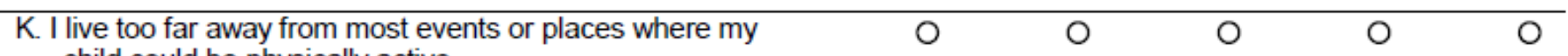
child could be physically active

$\begin{array}{llllll}\text { L.. When I was a child, I was very physically active } & 0 & 0 & 0 & 0 & 0\end{array}$

M. When I was a child, it was important to my parents that I was physically active

$0 \quad 0 \quad 0 \quad 0$

○

17. I feel it is a parent's responsibility to:

Disagree

Very

Strongly Disagree Neutral Agree Strongly

A. Enroll their child in sports or other organized activities that allows him/her to be physically active

B. Make sure their child is physically active at least 90 minutes every day

\begin{tabular}{|c|c|c|c|c|c|}
\hline C. Send their child outside to play on a regular basis & $\mathrm{O}$ & $\mathrm{O}$ & $\mathrm{O}$ & $\mathrm{O}$ & $\mathrm{O}$ \\
\hline D. Transport their child to physical activities on a regular basis & $\mathrm{O}$ & $\mathrm{O}$ & $\mathrm{O}$ & $\mathrm{O}$ & $\mathrm{O}$ \\
\hline E. Encourage their child to be physically active & $\mathrm{O}$ & $\mathrm{O}$ & $\mathrm{O}$ & $\mathrm{O}$ & $\mathrm{O}$ \\
\hline F. Require their child to do chores that involve physical activity & $\mathrm{O}$ & $\mathrm{O}$ & $\mathrm{O}$ & $\mathrm{O}$ & $\mathrm{O}$ \\
\hline $\begin{array}{l}\text { G. Make sure their child has access to equipment/toys that } \\
\text { encourage physical activity }\end{array}$ & $\mathrm{O}$ & $\mathrm{O}$ & $\mathrm{O}$ & $\mathrm{O}$ & $\mathrm{O}$ \\
\hline H. Make all decisions about what their child eats & $\mathrm{O}$ & $\mathrm{O}$ & $\mathrm{O}$ & $\mathrm{O}$ & $\mathrm{O}$ \\
\hline I. Keep track of how much their child eats & $\mathrm{O}$ & $\mathrm{O}$ & $\mathrm{O}$ & $\mathrm{O}$ & $\mathrm{O}$ \\
\hline J. Make sure their child eats fruits/vegetables every day & 0 & $\mathrm{O}$ & $\mathrm{O}$ & $\mathrm{O}$ & $\mathrm{O}$ \\
\hline K. Allow their child to eat what he/she wants & $\mathrm{O}$ & $\mathrm{O}$ & $\mathrm{O}$ & $\mathrm{O}$ & $\mathrm{O}$ \\
\hline
\end{tabular}

18. How important is it to YOU that your child is good at sports and physical activities?

O Not important at all O Not very important O Neutral O Somewhat important O Very important 
19. How much do YOU enjoy participating in sports and physical activity?

O Strongly dislikes O Dislikes O Somewhat dislikes O Somewhat likes O Likes O Strongly likes

\section{Please indicate HOW OFTEN you:}

A. Encourage your child to be physically active

Neverl

B. Transport your child to a place to be physically active

Never

Monthly Weekly Almost

C. Send vour child outside to plav

D. Give your child physical activity options

E. Praise your child for being physically active

O

F. Use physical activity as a reward

O

G. Use physical activity as a punishment

H. Take part in physical activity with your child

I. Use food as a reward

O

J. Use food as a punishment

O

K. Prepare meals with your child

$\mathrm{O} \quad \mathrm{O}$

L. Plan meals with your child

M. Offer healthy snacks

0

N. Eat a meal with your child

O. Schedule meal times

P. Allow your child free access to snacks

$0 \quad 0$

$0 \quad 0$

$\mathrm{O}$

0

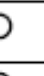

O

O $\mathrm{O}$

Q. Store fruits/vegetables in a place that is easily seen

$\mathrm{O} \quad \mathrm{O}$

0

R. Store fruits/vegetables in a place that is known but not seen

S. Watch your child play sports or be physically active

O

0

0

$\mathrm{O}$

O O

$\mathrm{O} O$

$0 \quad 0$

$\mathrm{O} \quad \mathrm{O} \quad \mathrm{O}$

$\mathrm{O}$

$\begin{array}{lllll}0 & 0 & 0 & 0 & 0\end{array}$

$0 \quad 0 \quad 0$

$0 \quad 0 \quad 0$

$\mathrm{O} \quad \mathrm{O} \quad \mathrm{O}$

$\mathrm{O} \quad \mathrm{O}$

0

O

$\mathrm{O}$

O

$\mathrm{O}$

$\mathrm{O}$

$\mathrm{O}$

21. On average, how often does your child do these activities?

\begin{tabular}{|c|c|c|c|c|c|c|c|}
\hline & Never & Rarely & Monthly & Weekly & Daily & $\begin{array}{c}\text { A few } \\
\text { times a day }\end{array}$ & $\begin{array}{c}\text { Many times } \\
\text { a day }\end{array}$ \\
\hline Walking & O & O & O & O & 0 & $\mathrm{O}$ & $\mathrm{O}$ \\
\hline Running & 0 & O & 0 & O & 0 & 0 & 0 \\
\hline Skipping & 0 & $\mathrm{O}$ & O & 0 & 0 & 0 & 0 \\
\hline Jumping & O & O & O & O & 0 & O & O \\
\hline Dancing & O & O & O & O & 0 & 0 & 0 \\
\hline Climbing & O & O & O & O & 0 & $\mathrm{O}$ & O \\
\hline Swimming & 0 & 0 & 0 & O & 0 & 0 & 0 \\
\hline Exercising & 0 & 0 & 0 & 0 & 0 & 0 & 0 \\
\hline
\end{tabular}


22. How often does your family eat fruits and/or vegetables: Never Rarely Sometimes Often Always

\begin{tabular}{llllll} 
A. At snack time & 0 & 0 & 0 & 0 & 0 \\
\hline B. At breakfast & 0 & 0 & 0 & 0 & 0 \\
\hline C. At lunch & 0 & 0 & 0 & 0 & 0 \\
\hline D. At dinner/supper & 0 & 0 & 0 & 0 & 0
\end{tabular}

23. How many total servings of fruits and vegetables do you think YOU should eat every day for good health? 23b. How many total servings of fruits and vegetables do you think YOUR CHILD should eat every day for good health?

24. Does your family grow fruits and/or vegetables at home?

O Never $O$ We have in the past but not anymore $O$ Most years $O$ Every year

25. Do you find it difficult to locate fresh fruits and/or vegetables in your community?

OYes O No

26. How many servings of fruits and/or vegetables do YOU eat every day?

27. How many servings of fruits and/or vegetables does YOUR CHILD eat every day?

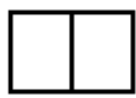

28. Does your child participate in the free or reduced lunch program?

O No OYes

29. How often do you and your child eat dark green vegetables (Example: spinach, arugula, romaine, mustard greens, collard greens, broccoli, green beans, asparagus, brussel sprouts, celery, green peppers, snap peas)?

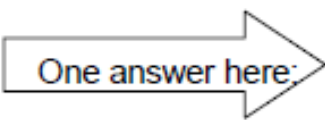

\begin{tabular}{cll}
$\frac{\text { Child }}{\mathrm{O}}$ & Less than once a week & Parent \\
0 & Once a week & 0 \\
\hline 0 & $2-3$ times a week & 0 \\
\hline 0 & $4-6$ times a week & 0 \\
\hline 0 & Once a day & 0 \\
\hline 0 & $2-3$ times a day & 0 \\
\hline 0 & 4-5 times a day & 0 \\
\hline 0 & 6 or more times a day & 0
\end{tabular}

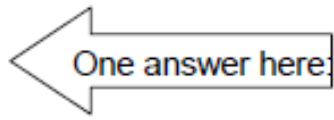

30. How often do you and your child eat red/purple vegetables

(Example: red peppers, beets, eggplant, tomatoes- including tomato juices and sauces)?

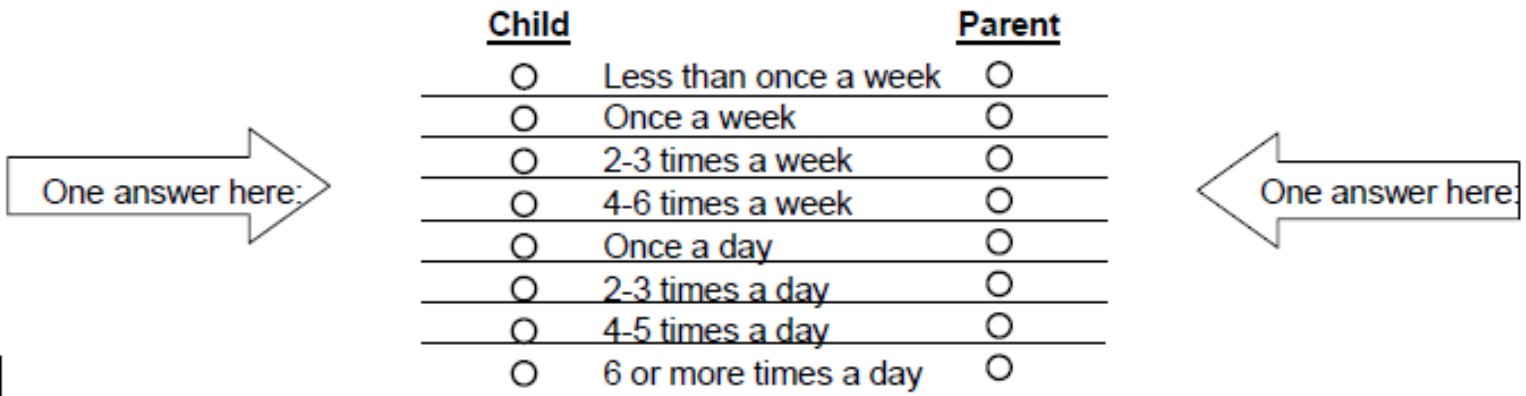


31. How often do you and your child eat starchy vegetables (Example: corn, peas, pinto beans, kidney beans, potatoes- including mashed, baked, fried)?

Child

Parent

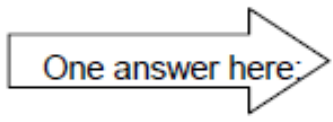

\begin{tabular}{cll}
0 & Less than once a week & 0 \\
\hline 0 & Once a week & 0 \\
\hline 0 & 2-3 times a week & 0 \\
\hline 0 & 4-6 times a week & 0 \\
\hline 0 & Once a day & 0 \\
\hline 0 & 2-3 times a day & 0 \\
\hline 0 & 4-5 times a day & 0 \\
\hline 0 & 6 or more times a day & 0
\end{tabular}

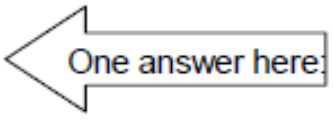

32. How often do you and your child eat other vegetables

(Example: artichokes, cabbage, cauliflower, cucumbers, mushrooms, onions, turnips, zucchini)?

\begin{tabular}{|c|c|c|c|}
\hline & Child & & Parent \\
\hline & $\mathrm{O}$ & Less than once a week & $\mathrm{O}$ \\
\hline \multirow{7}{*}{ One answer here.> } & $\mathrm{O}$ & Once a week & 0 \\
\hline & $\mathrm{O}$ & 2-3 times a week & $\mathrm{O}$ \\
\hline & 0 & 4-6 times a week & 0 \\
\hline & 0 & Once a day & $\mathrm{O}$ \\
\hline & 0 & 2-3 times a day & 0 \\
\hline & 0 & 4-5 times a day & 0 \\
\hline & 0 & 6 or more times a day & 0 \\
\hline
\end{tabular}

One answer here

33. How often do you and your child drink fruit juice (Example: orange, apple, grape, frozen, canned- not sodas, or other drinks)?

\begin{tabular}{|c|c|c|c|}
\hline 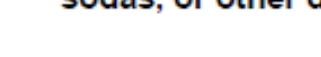 & Child & & Parent \\
\hline & $\mathrm{O}$ & Less than once a week & $\mathrm{O}$ \\
\hline & $\mathrm{O}$ & Once a week & $\mathrm{O}$ \\
\hline \multirow{6}{*}{ One answer here.> } & $\mathrm{O}$ & $2-3$ times a week & $\mathrm{O}$ \\
\hline & O & 4-6 times a week & $\mathrm{O}$ \\
\hline & $\mathrm{O}$ & Once a day & 0 \\
\hline & $\mathrm{O}$ & 2-3 times a day & $\mathrm{O}$ \\
\hline & 0 & $4-5$ times a day & 0 \\
\hline & O & 6 or more times a day & $\mathrm{O}$ \\
\hline
\end{tabular}

One answer here

34. How often do you and your child eat orange/yellow vegetables

(Example: carrots, sweet potatoes, acorn or butternut squash)?

\begin{tabular}{|c|c|c|c|}
\hline & Child & & Parent \\
\hline & 0 & Less than once a week & $\mathrm{O}$ \\
\hline \multirow{7}{*}{ One answer here: } & $\mathrm{O}$ & Once a week & $\mathrm{O}$ \\
\hline & $\mathrm{O}$ & 2-3 times a week & 0 \\
\hline & 0 & 4-6 times a week & 0 \\
\hline & 0 & Once a day & $\mathrm{O}$ \\
\hline & 0 & 2-3 times a day & 0 \\
\hline & 0 & 4-5 times a day & $\Omega$ \\
\hline & 0 & 6 or more times a day & 0 \\
\hline
\end{tabular}

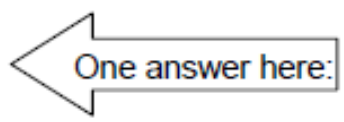


35. How often do you and your child eat fruit (Example: fresh, frozen, canned- not counting juice)?

Child $\quad$ Parent

\begin{tabular}{llll} 
& $\mathrm{O}$ & Once a week & $\mathrm{O}$ \\
\cline { 2 - 4 } One answer here: $>$ & $\mathrm{O}$ & 2-3 times a week & $\mathrm{O}$ \\
\hline $\mathrm{O}$ & 4-6 times a week & $\mathrm{O}$ \\
\hline $\mathrm{O}$ & Once a day & $\mathrm{O}$ \\
\hline $\mathrm{O}$ & 2-3 times a day & $\mathrm{O}$ \\
\hline $\mathrm{O}$ & 4-5 times a day & $\mathrm{O}$ \\
$\mathrm{O}$ & Gormore timesaday & $\mathrm{O}$
\end{tabular}

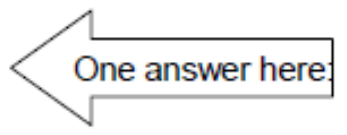

36. When you and your child eat fruits/vegetables, how often is it from a local source or from a home garden? Child

Parent

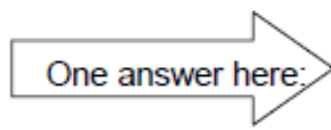

\begin{tabular}{|c|c|c|}
\hline $\mathrm{O}$ & Less than once a week & O \\
\hline $\mathrm{O}$ & Once a week & $\mathrm{O}$ \\
\hline $\mathrm{O}$ & 2-3 times a week & 0 \\
\hline 0 & 4-6 times a week & $\mathrm{O}$ \\
\hline $\mathrm{O}$ & Once a day & $\mathrm{O}$ \\
\hline 0 & 2-3 times a day & 0 \\
\hline $\mathrm{O}$ & 4-5 times a day & $\mathrm{O}$ \\
\hline $\mathrm{O}$ & 6 or more times a day & 0 \\
\hline
\end{tabular}

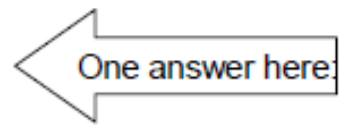

37. How often do you and your child eat out at restaurants or fast food places?

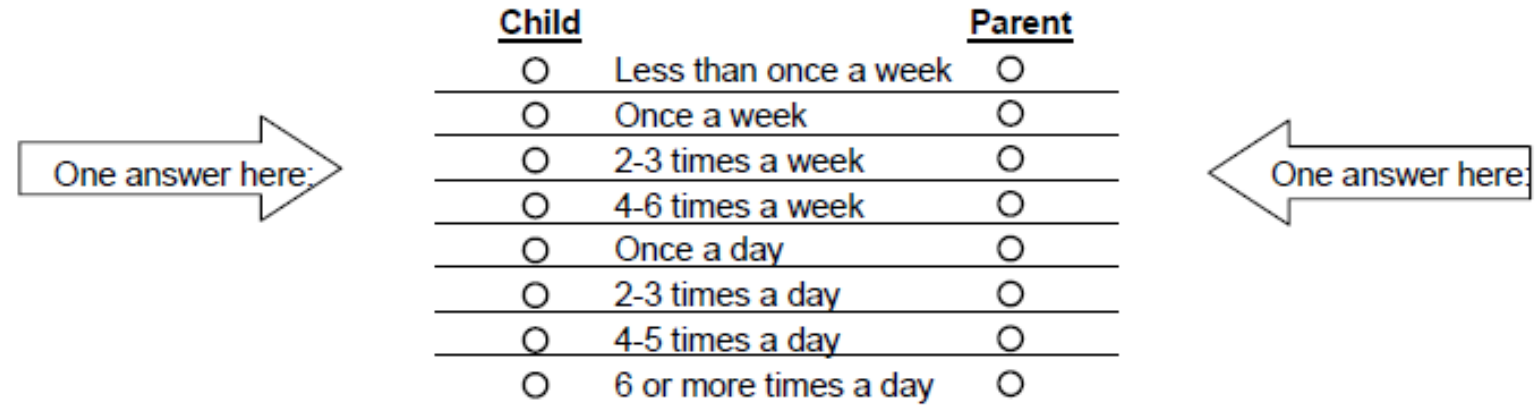

\section{THE FOLLOWING QUESTIONS WILL BE ABOUT SMOKING.}

38a. Have you smoked at least 100 cigarettes ( 5 packs) in your entire life?
O No OYes

38b. During the past 30 days, on how many days did you smoke cigarettes?
0 days
O 1 or 2 days
3 to 5 days
6 to 9 days
10 to 19 days
20 to 29 days
Every day

39. During the past 30 days, on the days that you smoked, how many cigarettes did you smoke per day?

I did not smoke cigarettes during the past 30 days

Less than 1 cigarrete per day

O 1 cigarrette per day

O 2 to 5 cigarettes per day

6 to 10 cigarettes per day

O 11 to 20 cigarettes per day

More than 20 cigarretes per day 
40. If you smoke, please mark all of the places where you have smoked in the last $\mathbf{3 0}$ days:

O Inside my home

O On my property but outside my home

O In my car

O At work

O Other:

\section{THE FOLLOWING QUESTIONS WILL BE ABOUT YOU AND YOUR PHYSICAL ACTIVITY.}

41. What is your:

Age:

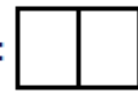

42. How would you describe your weight?

$\mathrm{O}$ Very underweight
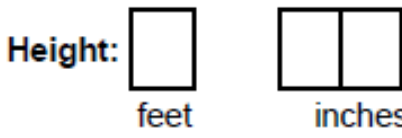

inches
Weight:

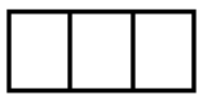

pounds

43. Please indicate how concerned you are about your weight?

O Very concerned O A little concerned O Not concerned

44. Does your job require you to be physically active? O Yes O No

45. On how many of the past 7 days did YOU exercise or participate in physical activities for at least $\mathbf{2 0}$ minutes that made you sweat and breathe hard, such as basketball, soccer, running, swimming, laps, fast bicycling, fast dancing, or similar aerobic activites?
$\bigcirc 0$ days
O 1 day
O 2 days
O 3 days
O 4 days
O 5 days
O 6 days
O days

46. On how many of the past 7 days did YOU participate in physical activity for at least $\mathbf{3 0}$ minutes that did NOT make you sweat or breathe hard, such as fast walking, slow bicycling, skating, pushing a lawn mower, or mopping floors?
$\mathrm{O} 0$ days
O 1 day $\quad 2$ days
O 3 days
O 4 days
O 5 days
O 6 days
O 7 days

47. Please rate your OWN physical activity level using a scale of 0 to 7 .
O 0
O 1
O 2
O 3
O 4
O 5
O 6
O 7

No activity

Very active

48. What is your approximate yearly household income?

O Less than $\$ 10,000 \quad \mathrm{O} \$ 35,000$ to $\$ 49,999$

O $\$ 10,000$ to $\$ 14,999 \quad \bigcirc \$ 50,000$ to $\$ 74,999$

O $\$ 15,000$ to $\$ 24,999 \quad \bigcirc \$ 75,000$ to $\$ 99,999$

O $\$ 25,000$ to $\$ 34,999$ O $\$ 100,000$ or more 
49. How many adults 19 and over live in your household: (including yourself)

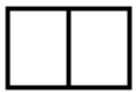

50. What are the ages of children (18 and under) in your household:

\begin{tabular}{|c|c|c|c|c|c|c|c|}
\hline & & & Age & & & & Age \\
\hline 1st child: & O Male & O Female & & 5th child: & O Male & O Female & \\
\hline 2nd child: & O Male & O Female & & 6th child: & O Male & O Female & \\
\hline 3rd child: & O Male & O Female & & 7th child: & O Male & O Female & \\
\hline 4th child: & O Male & O Female & & 8th child: & O Male & O Female & \\
\hline
\end{tabular}

THE FOLLOWING QUESTIONS ARE ABOUT YOUR CHILD'S ORGANIZED PHYSICAL ACTIVITIES.

Has your child ever participated in organized sports? O Yes O No

If yes, please complete the next section. If no, please go to the next page.

For each organized activity your child participates in, please indicate the number of years of participation, the average number of months out of the year your child was actively participation, and the average number of hours per week your child spent practicing or competing. If your child has never participated in the activity. please leave the box blank.

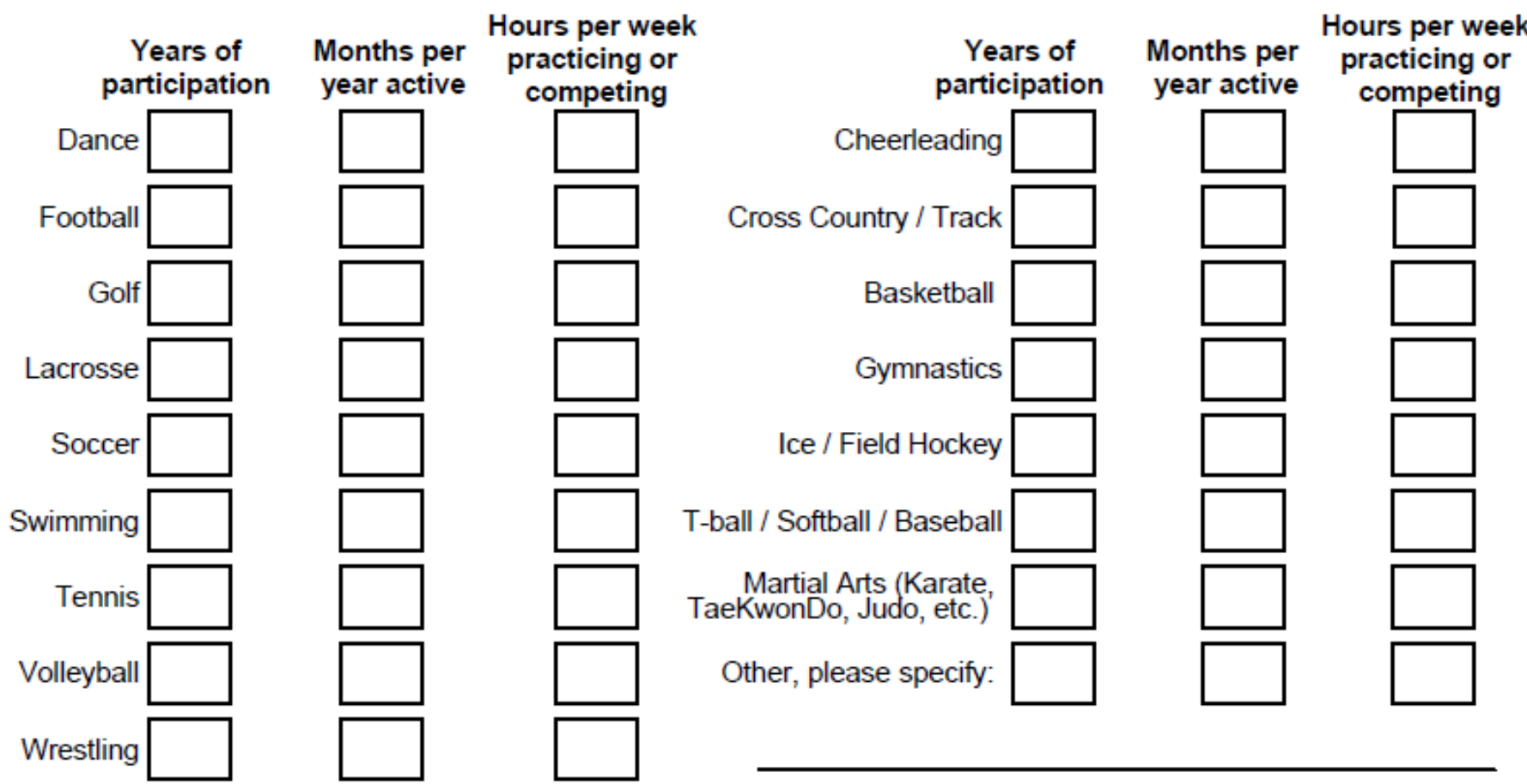


THE FOLLOWING QUESTIONS WILL BE ABOUT YOU FEEL ABOUT YOURSELF.

These statements allow people to describe themselves. There are no right or wrong answers since people differ a lot. First, decide which one of the statements in each pair best describes you. Then decide if this statement is "sort of true" or really true" about YOU.

1) O Some people feel extremely proud of who they are and what they can do physically.

1) O Others are sometimes not quite proud of who they are physically.

The statement I choose above is: O Really true for me

O Sort of true for me

2) O Some people are sometimes not so happy with the way they are or what they can do physically.

2) Others always feel happy about the kind of person they are physically.

The statement I choose above is: O Really true for me

O Sort of true for me

3) O When it comes to the physical side of themselves some people do not feel very confident. O Others seem to have a real sense of confidence in the physical side of themselves.

The statement I choose above is: O Really true for me

O Sort of true for me

4) O Some people always have a real positive feeling about the physical side of themselves.

O Others sometimes do not feel positive about the physical side of themselves.

The statement I choose above is: O Really true for me

O Sort of true for me

5) O Some people wish that they could have more respect for their physical selves.

O Others always have great respect for their physical selves.

The statement I choose above is: O Really true for me

O Sort of true for me

6) O Some people feel extremely satisfied with the kind of person they are physically.

O Others sometimes feel a little dissatisfied with their physical selves.

The statement I choose above is: O Really true for me

O Sort of true for me

Please indicate how strongly you agree or disagree with the following statements:

Strongly

Disagree

Disagree Agree

Strongly

Agree

A. I feel that I am a person of worth, at least on an equal plane with others.

B. I feel that I have a number of good qualities.

$\mathrm{O}$

O

$\mathrm{O}$

O

O

O

O

O

C. All in all, I am inclined to feel that I am a failure.

O

O

O

$\mathrm{O}$

D. I am able to do things as well as most other people.

$\mathrm{O}$

O

$\mathrm{O}$

O

E. I feel I do not have much to be proud of.

$\mathrm{O}$

O

O

O

F. I take a positive attitude toward myself.

$\mathrm{O}$

O

O

○

G. On the whole, I am satisfied with myself.

$\mathrm{O}$

O

O

O

H. I wish I could have more respect for myself.

$\mathrm{O}$

O

O

O

I. I certainly feel useless at times.

O

○

O

○

J. At times I think I am no good at all.

O

○

O

O

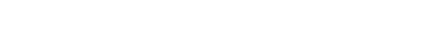

